\title{
A Pythagorean Fuzzy TOPSIS Method Based on Novel Correlation Measures and Its Application to Multiple Criteria Decision Analysis of Inpatient Stroke Rehabilitation
}

\author{
Yu-Li Lin ${ }^{1}$, Lun-Hui Ho ${ }^{2}$, Shu-Ling Yeh ${ }^{3}$, Ting-Yu Chen ${ }^{4}{ }^{*}$ \\ ${ }^{1}$ Department of Nursing, Linkou Chang Gung Memorial Hospital, Department of Nursing, Chang Gung University of Science and Technology, No.5, Fuxing St., Guishan \\ District, Taoyuan City 333, Taiwan \\ ${ }^{2}$ Department of Nursing, Linkou Chang Gung Memorial Hospital, Department of Nursing, Chang Gung University of Science and Technology, No.5, Fuxing St., Guishan \\ District, Taoyuan City 333, Taiwan \\ ${ }^{3}$ Department of Nursing, Linkou Chang Gung Memorial Hospital, Department of Nursing, Chang Gung University of Science and Technology, No.5, Fuxing St., Guishan \\ District, Taoyuan City 333, Taiwan \\ ${ }^{4}$ Graduate Institute of Business and Management, Chang Gung University, Department of Industrial and Business Management, Chang Gung University, Department of \\ Nursing, Linkou Chang Gung Memorial Hospital, No. 259, Wenhua 1st Rd., Guishan District, Taoyuan City 33302, Taiwan
}

\section{ARTICLE INFO}

\section{Article History}

Received 29 May 2018

Revised 15 Oct 2018

Accepted 24 Oct 2018

Keywords

Pythagorean fuzzy set

Multiple criteria decision analysis TOPSIS

Correlation measure

Inpatient stroke rehabilitation

\begin{abstract}
The complex nature of the realistic decision-making process requires the use of Pythagorean fuzzy $(\mathrm{PF})$ sets which have been shown to be a highly promising tool capable of solving highly vague and imprecise problems. Multiple criteria decision analysis (MCDA) methods within the PF environment are very attractive approaches for today's intricate decision environments. With this study, an effective compromise model named as the PF technique for order preference by similarity to ideal solutions (TOPSIS) is proposed based on some novel PF correlation-based concepts to overcome the complexities and ambiguities involved in real-life decision situations. In contrast to the existing distance-based definitions, this paper develops new closeness indices based on an extended concept of PF correlations. This paper employs the proposed PF correlation coefficients to construct two types of closeness measures. A comprehensive concept of PF correlation-based closeness indices can then be established to balance the consequences yielded by the two closeness measures. Based on these useful concepts, an effective PF TOPSIS method is proposed to address MCDA problems involving PF information and determine the ultimate priority orders among competing alternatives. Feasibility and practicability of the developed approach are illustrated by a medical decision-making problem of inpatient stroke rehabilitation. Finally, the proposed methodology is compared with other current methods to further explain its effectiveness.
\end{abstract}

(C) 2019 The Authors. Published by Atlantis Press SARL.

This is an open access article distributed under the CC BY-NC 4.0 license (http://creativecommons.org/licenses/by-nc/4.0/).

\section{INTRODUCTION}

Multiple criteria decision analysis (MCDA) concerns about evaluating discrete candidate alternatives and selecting the best compromise solution among a finite set of alternatives based on a finite set of criteria. There are numerous MCDA methods proposed by researchers in literature $[1,2]$. The technique for order preference by similarity to ideal solutions (TOPSIS), initiated by Hwang and Yoon [3] and later extended by Yoon [4] and Hwang et al. [5], is the most widely used compromise model in the MCDA field. TOPSIS ranks alternatives and determines the compromise solution that is the closest to the ideal solution. More precisely, the rationale of classical TOPSIS methods is that the best compromise alternative should have the shortest distance from the positive-ideal solution and the longest distance from the negative-ideal solution $[1,6,7]$.

\footnotetext{
${ }^{*}$ Corresponding author. Email: tychen@mail.cgu.edu.tw
}

TOPSIS has hitherto been widely studied by researchers and practitioners and have been successfully applied to several fields of real decision-makings [1, 7-11].

Regarding the uncertainty in real situations, many fuzzy extensions related studies have been explored to enrich the theory of TOPSIS methodology $[1,10,12]$. It is noteworthy that numerous realistic MCDA problems involve risks and uncertainties in nature [2, 13]. In this regard, the fuzzy set theory is very suitable and effective to handle the MCDA problems under vague, uncertain, and incomplete information environment. From this perspective, different versions of TOPSIS based on fuzzy sets have been developed for considering uncertainties and vagueness in MCDA problems, such as the fuzzy TOPSIS [14, 15], the generalized fuzzy TOPSIS [1], the analytic network process weighted fuzzy TOPSIS [16], the intuitionistic fuzzy TOPSIS $[7,9,17]$, the interval-valued intuitionistic fuzzy linguistic TOPSIS [18], the interval type-2 fuzzy TOPSIS [10, 12], and so on. Although numerous papers with fuzzy sets have been proposed for 
developing extensions of TOPSIS and applied to different application areas, relatively little attention has been paid to the extended TOPSIS dealing with MCDA problems under complex uncertainty based on Pythagorean fuzzy (PF) sets.

The concept of PF sets was introduced by Yager [19] and Yager and Abbasov [20]. PF sets are characterized by flexible degrees of membership, non-membership, and indeterminacy, in which the square sum of the degree of membership and the degree of nonmembership is less than or equal to one [19-21]. Since Zhang and Xu [22] proposed the general mathematical forms of PF sets, the PF theory has become increasingly popular in the MCDA field [23-25]. In particular, $\mathrm{PF}$ sets relax the constraint conditions and possess a great capability of managing high-order uncertainty in real-world decision situations $[21,23,24]$. Accordingly, many researchers have studied the MCDA methods within the PF decision environment $[21,24-31]$, and recently their popularity has grown among scholars owing to their high level of effectiveness [30, 31]. Nevertheless, relatively few studies focus on the development of the PF TOPSIS methodology.

Zhang and $\mathrm{Xu}$ [22] extended the TOPSIS method to effectively deal with the MCDA problems with PF sets and employed the revised closeness to identify the optimal alternative. Zeng et al. [32] combined the weighted average and ordered weighted averaging operator with distance measures to construct a PF- ordered weighted averaging weighted average distance operator and develop a hybrid TOPSIS method. Under the PF uncertainty, Liang and Xu [33] proposed a new concept of hesitant PF sets and explored their application to MCDA with the aid of the TOPSIS method. In particular, the three papers mentioned here employed the PF distance metrics as the separation measures to determine the degrees of relative closeness (or closeness coefficients) required in their proposed TOPSIS procedures. Based on the vertex method via Euclidean distances, Gul and Ak [34] developed a PF TOPSIS method to assess the hazards with respect to the parameters of likelihood and severity. By using the Hamming distance measure, Liang et al. [35] adopted the TOPSIS technique to estimate the conditional probability and propose a method for three-way decisions using ideal TOPSIS solutions at PF information. Zhou et al. [36] resembled the TOPSIS method, which considers the symmetry of the distances to the positive- and negative-ideal solutions, into their multiple criteria group decisionmaking method based on the Pythagorean normal cloud.

As is well known, the main approach in the classical TOPSIS procedure is to take the most preferred alternative which has the (weighted) minimum distance to the positive-ideal solution and the (weighted) maximum distance to the negative-ideal solution in a geometrical sense $[3,5]$. Central to the TOPSIS procedure is the relative closeness with respect to the ideal solutions. Accordingly, most existing studies on the TOPSIS models and techniques have focused on distance-based separation measures for determining the relative closeness (or closeness coefficients) and then ranking the preference orders among alternatives. Analogously, to solve MCDA problems within the PF environment, Gul and Ak [34], Liang and $\mathrm{Xu}$ [33], Liang et al. [35], Zeng et al. [32], Zhang and $\mathrm{Xu}$ [22], and Zhou et al. [36] also employed distance measures to determine degrees of relative closeness or revised closeness. Nevertheless, except for distance-based separation measures, the PF TOPSIS and other versions of TOPSIS extensions have not been yet sufficiently investigated for real-world MCDA problems in the PF context, which motivates the research of this paper.

This paper aims to present a useful extension of TOPSIS using novel PF correlation-based closeness indices and develops an effective PF TOPSIS method for managing MCDA problems under complex PF uncertainty. Different from the distance-based separation measures and traditional relative closeness, this paper defines a new closeness index based on the extended concept of PF correlations. The proposed PF correlations can fully reflect the relationship between $\mathrm{PF}$ information. By conducting a PF correlation analysis, the interdependency of an alternative with respect to the positive- and negative-ideal PF solutions can be appropriately examined with the aid of new closeness measures and PF correlation-based closeness indices. More specifically, this paper provides new definitions of (weighted) PF correlation coefficients for the purpose of developing certain useful concepts of (weighted) Type I and Type II closeness measures. Next, this paper constructs a comprehensive concept of (weighted) PF correlation-based closeness indices to acquire a balanced consequence between the obtained results via the (weighted) Type I and Type II closeness measures. A simple and effective PF TOPSIS method is then established to address MCDA problems involving PF information and further determine the ultimate priority orders of alternatives.

Finally, a practical medical decision-making problem concerning rehabilitation treatments for hospitalized patients with stroke and cerebrovascular diseases is provided to illustrate the effectiveness and feasibility of the proposed PF TOPSIS methodology. Stroke rehabilitation substantially contributes to the prevention of relapse as well as to patients' recovery, adaption to disability, and quality of life. This real-world application focuses on the treatment of patients with acute stroke and utilizes the PF TOPSIS method to evaluate the priority of various rehabilitation treatment measures for hospitalized patients. The application results can provide a useful decisionaiding suggestion for medical practitioners.

The remainder of this paper is organized as follows: Section 2 reviews some basic concepts related to PF sets that are used throughout this paper. Section 3 formulates an MCDA problem based on PF sets and presents the concept of the positive- and negative-ideal PF solutions. Section 4 introduces novel correlation measures named as the (weighted) PF correlation coefficients and explores their essential properties. Section 5 presents new PF correlation-based closeness indices and develops an effective PF TOPSIS method for managing MCDA problems within the PF decision environment. Section 6 applies the proposed method and techniques to address a practical medical decision-making problem concerning hospitalization rehabilitation treatments for stroke patients to demonstrate its feasibility and applicability. Finally, Section 7 presents the conclusions.

\section{PRELIMINARY DEFINITIONS}

This section introduces the basic concepts of PF sets and presents some arithmetic operations related to PF information.

Definition 1. [19, 20, 22, 24, 28] A PF set in a finite universe of discourse $X$ is an object having the following form:

$$
P=\left\{\left\langle x, \mu_{P}(x), \nu_{P}(x)\right\rangle \mid x \in X\right\},
$$


where $\mu_{P}(x): X \rightarrow[0,1]$ and $\nu_{P}(x): X \rightarrow[0,1]$ denote, respectively, the degree of membership and the degree of nonmembership with the condition:

$$
\left(\mu_{P}(x)\right)^{2}+\left(\nu_{P}(x)\right)^{2} \leq 1
$$

for each element $x \in X$. Let $p=\left(\mu_{P}(x), \nu_{P}(x)\right)$ denote a PF value. The degree of indeterminacy relative to $P$ for each $x \in X$ is defined as follows:

$$
\pi_{P}(x)=\sqrt{1-\left(\mu_{P}(x)\right)^{2}-\left(\nu_{P}(x)\right)^{2}} .
$$

The degree $\pi_{P}(x)$ expresses a lack of knowledge of whether the element $x$ belongs to $P$ or not.

Definition 2. [24, 26-28] Let $p_{1}, p_{2}$, and $p$ be three PF values in $X$ and $\alpha \geq 0$. Some basic arithmetic operations are defined as follows:

$$
\begin{aligned}
& p_{1} \vee p_{2}=\left(\max \left\{\mu_{P_{1}}(x), \mu_{P_{2}}(x)\right\}, \min \left\{v_{P_{1}}(x), \nu_{P_{2}}(x)\right\}\right), \\
& p_{1} \wedge p_{2}=\left(\min \left\{\mu_{P_{1}}(x), \mu_{P_{2}}(x)\right\}, \max \left\{\nu_{P_{1}}(x), \nu_{P_{2}}(x)\right\}\right) \\
& p_{1} \oplus p_{2}=\left(\left(\left(\mu_{P_{1}}(x)\right)^{2}+\left(\mu_{P_{2}}(x)\right)^{2}-\left(\mu_{P_{1}}(x)\right)^{2}\right.\right. \\
& \left.\left.\cdot\left(\mu_{P_{2}}(x)\right)^{2}\right)^{0.5}, \nu_{P_{1}}(x) \cdot v_{P_{2}}(x)\right) \\
& p_{1} \otimes p_{2}=\left(\mu_{P_{1}}(x) \cdot \mu_{P_{2}}(x),\left(\left(\nu_{P_{1}}(x)\right)^{2}+\left(\nu_{P_{2}}(x)\right)^{2}\right.\right. \\
& \left.\left.-\left(\nu_{P_{1}}(x)\right)^{2} \cdot\left(\nu_{P_{2}}(x)\right)^{2}\right)^{0.5}\right) \text {, } \\
& \alpha \cdot p=\left(\sqrt{1-\left(1-\left(\mu_{P}(x)\right)^{2}\right)^{\alpha}},\left(\nu_{P}(x)\right)^{\alpha}\right), \\
& p^{\alpha}=\left(\left(\mu_{P}(x)\right)^{\alpha}, \sqrt{1-\left(1-\left(\nu_{P}(x)\right)^{2}\right)^{\alpha}}\right)
\end{aligned}
$$

\section{DESCRIPTION OF PF MCDA PROBLEMS}

This section first describes an MCDA problem under complex uncertainty based on PF sets. Next, this section identifies the positive- and negative-ideal PF solutions as points of reference within the PF environment.

Consider an MCDA problem that contains a discrete set of $m(m \geq$ 2) candidate alternatives, expressed as $Z=\left\{z_{1}, z_{2}, \cdots, z_{m}\right\}$. Let $C=$ $\left\{c_{1}, c_{2}, \cdots, c_{n}\right\}$ be a finite set of $n(n \geq 2)$ evaluative criteria that have the weight vector $\mathrm{w}=\left(w_{1}, w_{2}, \cdots, w_{n}\right)$, where $w_{j} \in[0,1]$ for all $j \in\{1,2, \cdots, n\}$ and $\sum_{j=1}^{n} w_{j}=1$. Set $C$ can be generally divided into two sets, $C_{\mathrm{B}}$ and $C_{\mathrm{C}}$, where $C_{\mathrm{B}}$ denotes a collection of benefit criteria (i.e., larger values of $c_{j}$ indicate a greater preference), and $C_{\mathrm{C}}$ denotes a collection of cost criteria (i.e., smaller values of $c_{j}$ indicate a greater preference). Moreover, $C_{\mathrm{B}} \cap C_{\mathrm{C}}=\varnothing$ and $C_{\mathrm{B}} \cup C_{\mathrm{C}}=C$.
In the PF context, the MCDA problem consisting of PF values can be concisely represented in the following matrix form:

$$
\begin{aligned}
p & =\left[p_{i j}\right]_{m \times n} \\
& =\left[\begin{array}{cccc}
\left(\mu_{11}, \nu_{11}\right) & \left(\mu_{12}, \nu_{12}\right) & \ldots & \left(\mu_{1 n}, \nu_{1 n}\right) \\
\left(\mu_{21}, \nu_{21}\right) & \left(\mu_{22}, \nu_{22}\right) & \ldots & \left(\mu_{2 n}, v_{2 n}\right) \\
\vdots & \vdots & \ddots & \vdots \\
\left(\mu_{m 1}, \nu_{m 1}\right) & \left(\mu_{m 2}, \nu_{m 2}\right) & \cdots & \left(\mu_{m n}, v_{m n}\right)
\end{array}\right] .
\end{aligned}
$$

The element $p_{i j}=\left(\mu_{i j}, v_{i j}\right)$ in the PF decision matrix $\mathrm{p}$ indicates the evaluative rating of an alternative $z_{i} \in Z$ with respect to a criterion $c_{j} \in C$, where the degree of membership $\mu_{i j}$ and the degree of nonmembership $v_{i j}$ fulfill $\mu_{i j} \in[0,1], v_{i j} \in[0,1]$, and $\left(\mu_{i j}\right)^{2}+\left(\nu_{i j}\right)^{2} \leq$ 1 . The degree of indeterminacy that corresponds to each $p_{i j}$ is given by $\pi_{i j}=\sqrt{1-\left(\mu_{i j}\right)^{2}-\left(\nu_{i j}\right)^{2}}$. Furthermore, the PF characteristic $P_{i}$ of an alternative $z_{i}$ can be represented by all of the corresponding $\mathrm{PF}$ values as follows:

$$
\begin{aligned}
P_{i} & =\left\{\left\langle c_{1}, p_{i 1}\right\rangle,\left\langle c_{2}, p_{i 2}\right\rangle, \cdots,\left\langle c_{n}, p_{i n}\right\rangle\right\} \\
& =\left\{\left\langle c_{1},\left(\mu_{i 1}, \nu_{i 1}\right)\right\rangle,\left\langle c_{2},\left(\mu_{i 2}, v_{i 2}\right)\right\rangle, \cdots,\left\langle c_{n},\left(\mu_{i n}, v_{i n}\right)\right\rangle\right\} .
\end{aligned}
$$

Definition 3. Let $z_{+}$and $z_{-}$denote the positive- and negative-ideal $\mathrm{PF}$ solutions, respectively, with respect to a PF decision matrix $\mathrm{p}=$ $\left[\left(\mu_{i j}, v_{i j}\right)\right]_{m \times n}$. The PF characteristics of $z_{+}$and $z_{-}$are represented as follows:

$$
\begin{gathered}
P_{+}=\left\{\left\langle c_{1}, p_{+1}\right\rangle,\left\langle c_{2}, p_{+2}\right\rangle, \cdots,\left\langle c_{n}, p_{+n}\right\rangle\right\}, \\
P_{-}=\left\{\left\langle c_{1}, p_{-1}\right\rangle,\left\langle c_{2}, p_{-2}\right\rangle, \cdots,\left\langle c_{n}, p_{-n}\right\rangle\right\},
\end{gathered}
$$

where the positive- and negative-ideal PF values within $P_{+}$and $P_{-}$ are defined as follows:

$$
\begin{aligned}
& p_{+j}=\left(\mu_{+j}, \nu_{+j}\right)
\end{aligned}
$$

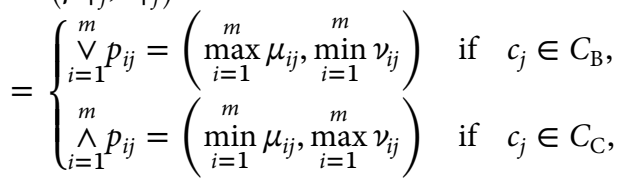

$$
\begin{aligned}
& p_{-j}=\left(\mu_{-j}, \nu_{-j}\right)
\end{aligned}
$$

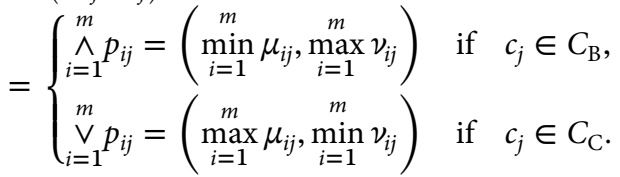

The respective degrees of indeterminacy corresponding to $p_{+j}$ and $p_{-j}$ are given by $\pi_{+j}=\sqrt{1-\left(\mu_{+j}\right)^{2}-\left(\nu_{+j}\right)^{2}}$ and $\pi_{-j}=$ $\sqrt{1-\left(\mu_{-j}\right)^{2}-\left(\nu_{-j}\right)^{2}}$.

\section{NOVEL PF CORRELATION COEFFICIENTS}

In the PF decision environment, this section attempts to develop new correlation measures named as the PF correlation coefficient and the weighted PF correlation coefficient. Some desirable and useful properties of these new measures are also investigated in this section. The (weighted) PF correlation coefficients can facilitate 
expressing not only a relative strength but also a positive or negative relationship between the two PF characteristics.

Definition 4. Let $P_{i_{1}}$ and $P_{i_{2}}$ be two PF characteristics in the PF decision matrix $\mathrm{p}$, where $P_{i_{1}}=$ $\left\{\left\langle c_{1},\left(\mu_{i_{1} 1}, \nu_{i_{1} 1}\right)\right\rangle, \quad\left\langle c_{2},\left(\mu_{i_{1} 2}, \nu_{i_{1} 2}\right)\right\rangle, \quad \cdots,\left\langle c_{n},\left(\mu_{i_{1} n}, \nu_{i_{1} n}\right)\right\rangle\right\}$ and $P_{i_{2}}=\left\{\left\langle c_{1},\left(\mu_{i_{2} 1}, v_{i_{2} 1}\right)\right\rangle,\left\langle c_{2},\left(\mu_{i_{2} 2}, v_{i_{2} 2}\right)\right\rangle, \cdots,\left\langle c_{n},\left(\mu_{i_{2} n}, v_{i_{2} n}\right)\right\rangle\right\}$. Let $\bar{\mu}_{j}=\sum_{i=1}^{m} \mu_{i j} / m, \bar{\nu}_{j}=\sum_{i=1}^{m} \nu_{i j} / m$, and $\bar{\pi}_{j}=\sum_{i=1}^{m} \pi_{i j} / m$. The PF correlation coefficient $\gamma\left(P_{i_{1}}, P_{i_{2}}\right)$ between $P_{i_{1}}$ and $P_{i_{2}}$ is defined as follows:

$\gamma\left(P_{i_{1}}, P_{i_{2}}\right)=\frac{1}{3}\left(r_{\mu}\left(P_{i_{1}}, P_{i_{2}}\right)+r_{\nu}\left(P_{i_{1}}, P_{i_{2}}\right)+r_{\pi}\left(P_{i_{1}}, P_{i_{2}}\right)\right)$,

where

$$
\begin{aligned}
& r_{\mu}\left(P_{i_{1}}, P_{i_{2}}\right) \\
& =\frac{\sum_{j=1}^{n}\left(\left(\mu_{i_{1} j}\right)^{2}-\left(\bar{\mu}_{j}\right)^{2}\right) \cdot\left(\left(\mu_{i_{2} j}\right)^{2}-\left(\bar{\mu}_{j}\right)^{2}\right)}{\sqrt{\sum_{j=1}^{n}\left(\left(\mu_{i_{1} j}\right)^{2}-\left(\bar{\mu}_{j}\right)^{2}\right)^{2}} \cdot \sqrt{\sum_{j=1}^{n}\left(\left(\mu_{i_{2} j}\right)^{2}-\left(\bar{\mu}_{j}\right)^{2}\right)^{2}}}, \\
& \begin{array}{l}
r_{\nu}\left(P_{i_{1}}, P_{i_{2}}\right) \\
=\frac{\sum_{j=1}^{n}\left(\left(\nu_{i_{1} j}\right)^{2}-\left(\bar{v}_{j}\right)^{2}\right) \cdot\left(\left(\nu_{i_{2} j}\right)^{2}-\left(\bar{\nu}_{j}\right)^{2}\right)}{\sqrt{\sum_{j=1}^{n}\left(\left(\nu_{i_{1} j}\right)^{2}-\left(\bar{\nu}_{j}\right)^{2}\right)^{2}} \cdot \sqrt{\sum_{j=1}^{n}\left(\left(\nu_{i_{2} j}\right)^{2}-\left(\bar{\nu}_{j}\right)^{2}\right)^{2}}},
\end{array} \\
& r_{\pi}\left(P_{i_{1}}, P_{i_{2}}\right) \\
& =\frac{\sum_{j=1}^{n}\left(\left(\pi_{i_{1} j}\right)^{2}-\left(\bar{\pi}_{j}\right)^{2}\right) \cdot\left(\left(\pi_{i_{2} j}\right)^{2}-\left(\bar{\pi}_{j}\right)^{2}\right)}{\sqrt{\sum_{j=1}^{n}\left(\left(\pi_{i_{1} j}\right)^{2}-\left(\bar{\pi}_{j}\right)^{2}\right)^{2}} \cdot \sqrt{\sum_{j=1}^{n}\left(\left(\pi_{i_{2} j}\right)^{2}-\left(\bar{\pi}_{j}\right)^{2}\right)^{2}}} .
\end{aligned}
$$

It is worth noting that this paper avoids zero in the denominators of the membership component $r_{\mu}\left(P_{i_{1}}, P_{i_{2}}\right)$, the nonmembership component $r_{\nu}\left(P_{i_{1}}, P_{i_{2}}\right)$, and the indeterminacy component $r_{\pi}\left(P_{i_{1}}, P_{i_{2}}\right)$ with respect to each $\gamma\left(P_{i_{1}}, P_{i_{2}}\right)$ without loss of generality.

Theorem 1. The membership component $r_{\mu}\left(P_{i_{1}}, P_{i_{2}}\right)$ in the PF correlation coefficient $\gamma\left(P_{i_{1}}, P_{i_{2}}\right)$ for two $P F$ characteristics $P_{i_{1}}$ and $P_{i_{2}}$ satisfies the following properties:

- (T1.1) $r_{\mu}\left(P_{i_{1}}, P_{i_{2}}\right)=r_{\mu}\left(P_{i_{2}}, P_{i_{1}}\right)$;

- (T1.2) $r_{\mu}\left(P_{i_{1}}, P_{i_{2}}\right)=1$ if $\mu_{i_{1} j}=\mu_{i_{2} j}$ for all $c_{j} \in C$;

- (T1.3) $\left|r_{\mu}\left(P_{i_{1}}, P_{i_{2}}\right)\right| \leq 1$.
Proof. (T1.1) is trivial. (T1.2) can be easily checked because:

$$
r_{\mu}\left(P_{i_{1}}, P_{i_{2}}\right)=\frac{\sum_{j=1}^{n}\left(\left(\mu_{i_{2} j}\right)^{2}-\left(\bar{\mu}_{j}\right)^{2}\right)^{2}}{\left(\sqrt{\sum_{j=1}^{n}\left(\left(\mu_{i_{2} j}\right)^{2}-\left(\bar{\mu}_{j}\right)^{2}\right)^{2}}\right)^{2}}=1 .
$$

For (T1.3), it is clearly known that $0 \leq\left(\mu_{i j}\right)^{2} \leq 1$ and $0 \leq$ $\left(\bar{\mu}_{j}\right)^{2} \leq 1$ because $\mu_{i j} \in[0,1]$ and $\bar{\mu}_{j}=\sum_{i=1}^{m} \mu_{i j} / m$. Hence, it follows that $-1 \leq\left(\mu_{i_{1} j}\right)^{2}-\left(\bar{\mu}_{j}\right)^{2} \leq 1$ and $-1 \leq\left(\mu_{i_{2} j}\right)^{2}-$ $\left(\bar{\mu}_{j}\right)^{2} \leq 1$. One can easily infer that $0 \leq\left(\left(\mu_{i_{1} j}\right)^{2}-\left(\bar{\mu}_{j}\right)^{2}\right)^{2} \leq$ 1 and $0 \leq\left(\left(\mu_{i_{2} j}\right)^{2}-\left(\bar{\mu}_{j}\right)^{2}\right)^{2} \leq 1$, which lead to $-1 \leq$ $\left(\left(\mu_{i_{1} j}\right)^{2}-\left(\bar{\mu}_{j}\right)^{2}\right) \cdot\left(\left(\mu_{i_{2} j}\right)^{2}-\left(\bar{\mu}_{j}\right)^{2}\right) \leq 1$. Thus, the range of the numerator in Equation (17) will be $-n \leq \sum_{j=1}^{n}\left(\left(\mu_{i_{1} j}\right)^{2}-\left(\bar{\mu}_{j}\right)^{2}\right)$. $\left(\left(\mu_{i_{2} j}\right)^{2}-\left(\bar{\mu}_{j}\right)^{2}\right) \leq n$. Next, consider the denominator in Equation (17). By means of $0 \leq\left(\left(\mu_{i_{1} j}\right)^{2}-\left(\bar{\mu}_{j}\right)^{2}\right)^{2} \leq 1$ and $0 \leq\left(\left(\mu_{i_{2} j}\right)^{2}-\left(\bar{\mu}_{j}\right)^{2}\right)^{2} \leq 1$, the following results are correct: $0 \leq$ $\sum_{j=1}^{n}\left(\left(\mu_{i_{1} j}\right)^{2}-\left(\bar{\mu}_{j}\right)^{2}\right)^{2} \leq n$ and $0 \leq \sum_{j=1}^{n}\left(\left(\mu_{i_{2} j}\right)^{2}-\left(\bar{\mu}_{j}\right)^{2}\right)^{2} \leq n$. Thus, $\sqrt{\sum_{j=1}^{n}\left(\left(\mu_{i_{1} j}\right)^{2}-\left(\bar{\mu}_{j}\right)^{2}\right)^{2}} \cdot \sqrt{\sum_{j=1}^{n}\left(\left(\mu_{i_{2} j}\right)^{2}-\left(\bar{\mu}_{j}\right)^{2}\right)^{2}} \leq$ $\sqrt{n} \cdot \sqrt{n}=n$. Consequently, it can be concluded that $-1 \leq$ $r_{\mu}\left(P_{i_{1}}, P_{i_{2}}\right) \leq 1$, that is, $\left|r_{\mu}\left(P_{i_{1}}, P_{i_{2}}\right)\right| \leq 1$. This establishes the theorem.

Theorem 2. The nonmembership component $r_{\nu}\left(P_{i_{1}}, P_{i_{2}}\right)$ in the PF correlation coefficient $\gamma\left(P_{i_{1}}, P_{i_{2}}\right)$ for two PF characteristics $P_{i_{1}}$ and $P_{i_{2}}$ satisfies the following properties:

- (T2.1) $r_{\nu}\left(P_{i_{1}}, P_{i_{2}}\right)=r_{\nu}\left(P_{i_{2}}, P_{i_{1}}\right)$;

- (T2.2) $r_{\nu}\left(P_{i_{1}}, P_{i_{2}}\right)=1$ if $v_{i_{1} j}=v_{i_{2} j}$ for all $c_{j} \in C$;

- (T2.3) $\left|r_{\nu}\left(P_{i_{1}}, P_{i_{2}}\right)\right| \leq 1$.

Proof. The proofs of this theorem are analogous to those of Theorem 1.

Theorem 3. The indeterminacy component $r_{\pi}\left(P_{i_{1}}, P_{i_{2}}\right)$ in the PF correlation coefficient $\gamma\left(P_{i_{1}}, P_{i_{2}}\right)$ for two PF characteristics $P_{i_{1}}$ and $P_{i_{2}}$ satisfies the following properties:

- (T3.1) $r_{\pi}\left(P_{i_{1}}, P_{i_{2}}\right)=r_{\pi}\left(P_{i_{2}}, P_{i_{1}}\right)$;

- (T3.2) $r_{\pi}\left(P_{i_{1}}, P_{i_{2}}\right)=1$ if $\pi_{i_{1} j}=\pi_{i_{2} j}$ for all $c_{j} \in C$;

- (T3.3) $\left|r_{\pi}\left(P_{i_{1}}, P_{i_{2}}\right)\right| \leq 1$. 
Proof. The proofs of this theorem are analogous to those of Theorem 1.

Theorem 4. The PF correlation coefficient $\gamma\left(P_{i_{1}}, P_{i_{2}}\right)$ between two $P F$ characteristics $P_{i_{1}}$ and $P_{i_{2}}$ satisfies the following properties:

- (T4.1) $\gamma\left(P_{i_{1}}, P_{i_{2}}\right)=\gamma\left(P_{i_{2}}, P_{i_{1}}\right)$;

- (T4.2) $\gamma\left(P_{i_{1}}, P_{i_{2}}\right)=1$ if $P_{i_{1}}=P_{i_{2}}$;

- (T4.3) $\left|\gamma\left(P_{i_{1}}, P_{i_{2}}\right)\right| \leq 1$.

Proof. (T4.1) is straightforward from (T1.1), (T2.1), and (T3.1). For (T4.2), the assumption $P_{i_{1}}=P_{i_{2}}$ means that $\mu_{i_{1} j}=\mu_{i_{2} j}, \nu_{i_{1} j}=\nu_{i_{2} j}$, and $\pi_{i_{1} j}=\pi_{i_{2} j}$ hold for all $c_{j} \in C$. According to (T1.2), (T2.2), and (T3.2), one obtains $r_{\mu}\left(P_{i_{1}}, P_{i_{2}}\right)=r_{\nu}\left(P_{i_{1}}, P_{i_{2}}\right)=r_{\pi}\left(P_{i_{1}}, P_{i_{2}}\right)=$ 1 , which brings about $\gamma\left(P_{i_{1}}, P_{i_{2}}\right)=1$. Thus, (T4.2) is valid. For (T4.3), based on the results of (T1.3), (T2.3), and (T3.3), one can infer that $\left|\gamma\left(P_{i_{1}}, P_{i_{2}}\right)\right| \leq 1$, i.e., (T4.3) is valid. This completes the proof.

Furthermore, this paper incorporates the weight vector $\mathrm{w}=$ $\left(w_{1}, w_{2}, \cdots, w_{n}\right)$ into the correlation measure to propose the weighted PF correlation coefficient between two PF characteristics.

Definition 5. Let $P_{i_{1}}$ and $P_{i_{2}}$ be two PF characteristics in the PF decision matrix $\mathrm{p}$, and let $w_{j}$ be the importance weight of criterion $c_{j} \in C$ with $w_{j} \in[0,1]$ and $\sum_{j=1}^{n} w_{j}=1$. The weighted PF correlation coefficient $\gamma^{w}\left(P_{i_{1}}, P_{i_{2}}\right)$ between $P_{i_{1}}$ and $P_{i_{2}}$ is defined as follows:

$$
\gamma^{w}\left(P_{i_{1}}, P_{i_{2}}\right)=\frac{1}{3}\left(r_{\mu}^{w}\left(P_{i_{1}}, P_{i_{2}}\right)+r_{\nu}^{w}\left(P_{i_{1}}, P_{i_{2}}\right)+r_{\pi}^{w}\left(P_{i_{1}}, P_{i_{2}}\right)\right),
$$

where

$$
\begin{aligned}
& r_{\mu}^{w}\left(P_{i_{1}}, P_{i_{2}}\right) \\
& =\left(\sum_{j=1}^{n} w_{j}\left(\left(\mu_{i_{1} j}\right)^{2}-\left(\bar{\mu}_{j}\right)^{2}\right) \cdot\left(\left(\mu_{i_{2} j}\right)^{2}-\left(\bar{\mu}_{j}\right)^{2}\right)\right) / \\
& \left(\sqrt{\sum_{j=1}^{n} w_{j}\left(\left(\mu_{i_{1} j}\right)^{2}-\left(\bar{\mu}_{j}\right)^{2}\right)^{2}}\right. \text {. } \\
& \sqrt{\sum_{j=1}^{n} w_{j}\left(\left(\mu_{i_{2} j}\right)^{2}-\left(\bar{\mu}_{j}\right)^{2}\right)^{2}}, \\
& r_{\nu}^{w}\left(P_{i_{1}}, P_{i_{2}}\right) \\
& =\left(\sum_{j=1}^{n} w_{j}\left(\left(\nu_{i_{1} j}\right)^{2}-\left(\bar{v}_{j}\right)^{2}\right) \cdot\left(\left(\nu_{i_{2} j}\right)^{2}-\left(\bar{\nu}_{j}\right)^{2}\right)\right) / \\
& \left(\sqrt{\sum_{j=1}^{n} w_{j}\left(\left(\nu_{i_{1} j}\right)^{2}-\left(\bar{\nu}_{j}\right)^{2}\right)^{2}}\right. \text {. } \\
& \left.\sqrt{\sum_{j=1}^{n} w_{j}\left(\left(\nu_{i_{2}}\right)^{2}-\left(\bar{v}_{j}\right)^{2}\right)^{2}}\right) \text {, }
\end{aligned}
$$

$$
\begin{aligned}
r_{\pi}^{w}\left(P_{i_{1}}, P_{i_{2}}\right) & \left(\sum_{j=1}^{n} w_{j}\left(\left(\pi_{i_{1} j}\right)^{2}-\left(\bar{\pi}_{j}\right)^{2}\right) \cdot\left(\left(\pi_{i_{2} j}\right)^{2}-\left(\bar{\pi}_{j}\right)^{2}\right)\right) / \\
& \left(\sqrt{\sum_{j=1}^{n} w_{j}\left(\left(\pi_{i_{1} j}\right)^{2}-\left(\bar{\pi}_{j}\right)^{2}\right)^{2}} .\right. \\
& \left.\sqrt{\sum_{j=1}^{n} w_{j}\left(\left(\pi_{i_{2} j}\right)^{2}-\left(\bar{\pi}_{j}\right)^{2}\right)^{2}}\right) .
\end{aligned}
$$

Analogous to the unweighted situation, this paper avoids zero in the denominators of the membership component $r_{\mu}^{w}\left(P_{i_{1}}, P_{i_{2}}\right)$, the nonmembership component $r_{\nu}^{w}\left(P_{i_{1}}, P_{i_{2}}\right)$, and the indeterminacy component $r_{\pi}^{w}\left(P_{i_{1}}, P_{i_{2}}\right)$ with respect to each $\gamma^{w}\left(P_{i_{1}}, P_{i_{2}}\right)$ without loss of generality.

Theorem 5. The membership component $r_{\mu}^{w}\left(P_{i_{1}}, P_{i_{2}}\right)$ in the weighted PF correlation coefficient $\gamma^{w}\left(P_{i_{1}}, P_{i_{2}}\right)$ for two PF characteristics $P_{i_{1}}$ and $P_{i_{2}}$ satisfies the following properties:

- (T5.1) $r_{\mu}^{w}\left(P_{i_{1}}, P_{i_{2}}\right)=r_{\mu}^{w}\left(P_{i_{2}}, P_{i_{1}}\right)$;

- (T5.2) $r_{\mu}^{w}\left(P_{i_{1}}, P_{i_{2}}\right)=1$ if $\mu_{i_{1} j}=\mu_{i_{2} j}$ for all $c_{j} \in C$;

- (T5.3) $\left|r_{\mu}^{w}\left(P_{i_{1}}, P_{i_{2}}\right)\right| \leq 1$;

- (T5.4) $r_{\mu}^{w}\left(P_{i_{1}}, P_{i_{2}}\right)=r_{\mu}\left(P_{i_{1}}, P_{i_{2}}\right)$ if $w=(1 / n, 1 / n, \cdots, 1 / n)$.

Proof. (T5.1) is trivial. (T5.2) is obvious because:

$$
\begin{aligned}
& r_{\mu}^{w}\left(P_{i_{1}}, P_{i_{2}}\right) \\
& =\left(\sum_{j=1}^{n} w_{j}\left(\left(\mu_{i_{2} j}\right)^{2}-\left(\bar{\mu}_{j}\right)^{2}\right)^{2}\right) / \\
& \left(\sqrt{\sum_{j=1}^{n} w_{j}\left(\left(\mu_{i_{2} j}\right)^{2}-\left(\bar{\mu}_{j}\right)^{2}\right)^{2}}\right)^{2}=1 .
\end{aligned}
$$

For (T5.3), based on the previous discussion in the proving process of (T1.3), one obtains $-1 \leq\left(\left(\mu_{i_{1} j}\right)^{2}-\left(\bar{\mu}_{j}\right)^{2}\right)$. $\left(\left(\mu_{i_{2} j}\right)^{2}-\left(\bar{\mu}_{j}\right)^{2}\right) \leq 1$. Because $\sum_{j=1}^{n} w_{j}=1$, the range of the numerator in Equation (21) will be $-1 \leq$ $\sum_{j=1}^{n} w_{j}\left(\left(\mu_{i_{1} j}\right)^{2}-\left(\bar{\mu}_{j}\right)^{2}\right) \cdot\left(\left(\mu_{i_{2} j}\right)^{2}-\left(\bar{\mu}_{j}\right)^{2}\right) \leq 1$. Consider the component in the denominator of Equation (21). Because $0 \leq$ $\sum_{j=1}^{n}\left(\left(\mu_{i_{1} j}\right)^{2}-\left(\bar{\mu}_{j}\right)^{2}\right)^{2} \leq n$ and $0 \leq \sum_{j=1}^{n}\left(\left(\mu_{i_{2} j}\right)^{2}-\left(\bar{\mu}_{j}\right)^{2}\right)^{2} \leq n$ based on the obtained results in the proving process of (T1.3), one has $0 \leq \sum_{j=1}^{n} w_{j}\left(\left(\mu_{i_{1} j}\right)^{2}-\left(\bar{\mu}_{j}\right)^{2}\right)^{2} \leq 1$ and $0 \leq \sum_{j=1}^{n} w_{j}\left(\left(\mu_{i_{2} j}\right)^{2}-\left(\bar{\mu}_{j}\right)^{2}\right)^{2} \leq 1$. If follows that $0 \leq$ $\left[\sum_{j=1}^{n} w_{j}\left(\left(\mu_{i_{1} j}\right)^{2}-\left(\bar{\mu}_{j}\right)^{2}\right)^{2}\right]^{1 / 2} \cdot\left[\sum_{j=1}^{n} w_{j}\left(\left(\mu_{i_{2} j}\right)^{2}-\left(\bar{\mu}_{j}\right)^{2}\right)^{2}\right]^{1 / 2} \leq$ 1. Recall that this paper avoids zero in the denominator of $r_{\mu}^{w}\left(P_{i_{1}}, P_{i_{2}}\right)$. Hence, (T5.3) is valid because $-1 \leq r_{\mu}^{w}\left(P_{i_{1}}, P_{i_{2}}\right) \leq 1$ 
(i.e. $\left.\left|r_{\mu}^{w}\left(P_{i_{1}}, P_{i_{2}}\right)\right| \leq 1\right)$. For (T5.4), when the weight vector $\mathrm{w}=(1 / n, 1 / n, \cdots, 1 / n)$, the membership component $r_{\mu}^{w}\left(P_{i_{1}}, P_{i_{2}}\right)$ becomes:

$$
\begin{aligned}
& r_{\mu}^{w}\left(P_{i_{1}}, P_{i_{2}}\right) \\
& =\left(\sum_{j=1}^{n} \frac{1}{n}\left(\left(\mu_{i_{1} j}\right)^{2}-\left(\bar{\mu}_{j}\right)^{2}\right) \cdot\left(\left(\mu_{i_{2} j}\right)^{2}-\left(\bar{\mu}_{j}\right)^{2}\right)\right) / \\
& \left(\sqrt{\sum_{j=1}^{n} \frac{1}{n}\left(\left(\mu_{i_{1} j}\right)^{2}-\left(\bar{\mu}_{j}\right)^{2}\right)^{2}}\right. \text {. } \\
& \sqrt{\sum_{j=1}^{n} \frac{1}{n}\left(\left(\mu_{i_{2} j}\right)^{2}-\left(\bar{\mu}_{j}\right)^{2}\right)^{2}} \\
& =\frac{1}{n} \cdot\left(\sum_{j=1}^{n}\left(\left(\mu_{i_{1} j}\right)^{2}-\left(\bar{\mu}_{j}\right)^{2}\right) \cdot\left(\left(\mu_{i_{2} j}\right)^{2}-\left(\bar{\mu}_{j}\right)^{2}\right)\right) / \\
& \left(\left(\sqrt{\frac{1}{n}}\right)^{2} \cdot \sqrt{\sum_{j=1}^{n}\left(\left(\mu_{i_{1} j}\right)^{2}-\left(\bar{\mu}_{j}\right)^{2}\right)^{2}} .\right. \\
& \sqrt{\sum_{j=1}^{n}\left(\left(\mu_{i_{2} j}\right)^{2}-\left(\bar{\mu}_{j}\right)^{2}\right)^{2}}=r_{\mu}\left(P_{i_{1}}, P_{i_{2}}\right) \text {. }
\end{aligned}
$$

Therefore, (T5.4) is valid, which completes the proof.

Theorem 6. The nonmembership component $r_{\nu}^{w}\left(P_{i_{1}}, P_{i_{2}}\right)$ in the weighted PF correlation coefficient $\gamma^{w}\left(P_{i_{1}}, P_{i_{2}}\right)$ for two PF characteristics $P_{i_{1}}$ and $P_{i_{2}}$ satisfies the following properties:

- (T6.1) $r_{\nu}^{w}\left(P_{i_{1}}, P_{i_{2}}\right)=r_{\nu}^{w}\left(P_{i_{2}}, P_{i_{1}}\right)$;

- (T6.2) $r_{\nu}^{w}\left(P_{i_{1}}, P_{i_{2}}\right)=1$ if $v_{i_{1} j}=v_{i_{2} j}$ for all $c_{j} \in C$;

- (T6.3) $\left|r_{\nu}^{w}\left(P_{i_{1}}, P_{i_{2}}\right)\right| \leq 1$;

- (T6.4) $r_{\nu}^{w}\left(P_{i_{1}}, P_{i_{2}}\right)=r_{\nu}\left(P_{i_{1}}, P_{i_{2}}\right)$ if $w=(1 / n, 1 / n, \cdots, 1 / n)$.

Proof. The proofs of this theorem are analogous to those of Theorem 5.

Theorem 7. The indeterminacy component $r_{\pi}^{w}\left(P_{i_{1}}, P_{i_{2}}\right)$ in the weighted PF correlation coefficient $\gamma^{w}\left(P_{i_{1}}, P_{i_{2}}\right)$ for two PF characteristics $P_{i_{1}}$ and $P_{i_{2}}$ satisfies the following properties:

- (T7.1) $r_{\pi}^{w}\left(P_{i_{1}}, P_{i_{2}}\right)=r_{\pi}^{w}\left(P_{i_{2}}, P_{i_{1}}\right)$;

- (T7.2) $r_{\pi}^{w}\left(P_{i_{1}}, P_{i_{2}}\right)=1$ if $\pi_{i_{1} j}=\pi_{i_{2} j}$ for all $c_{j} \in C$;

- (T7.3) $\left|r_{\pi}^{w}\left(P_{i_{1}}, P_{i_{2}}\right)\right| \leq 1$;

- (T7.4) $r_{\pi}^{w}\left(P_{i_{1}}, P_{i_{2}}\right)=r_{\pi}\left(P_{i_{1}}, P_{i_{2}}\right)$ if $w=(1 / n, 1 / n, \cdots, 1 / n)$.

Proof. The proofs of this theorem are analogous to those of Theorem 5.

Theorem 8. The weighted PF correlation coefficient $\gamma^{w}\left(P_{i_{1}}, P_{i_{2}}\right)$ between two PF characteristics $P_{i_{1}}$ and $P_{i_{2}}$ satisfies the following properties:

- $\quad(T 8.1) \gamma^{w}\left(P_{i_{1}}, P_{i_{2}}\right)=\gamma^{w}\left(P_{i_{2}}, P_{i_{1}}\right)$;

- $\left(\right.$ T8.2) $\gamma^{w}\left(P_{i_{1}}, P_{i_{2}}\right)=1$ if $P_{i_{1}}=P_{i_{2}}$;
- $(T 8.3)\left|\gamma^{w}\left(P_{i_{1}}, P_{i_{2}}\right)\right| \leq 1$;

- $($ T8.4 $) \gamma^{w}\left(P_{i_{1}}, P_{i_{2}}\right)=\gamma\left(P_{i_{1}}, P_{i_{2}}\right)$ if $w=(1 / n, 1 / n, \cdots, 1 / n)$.

Proof. (T8.1) is straightforward from (T5.1), (T6.1), and (T7.1). For (T8.2), the assumption $P_{i_{1}}=P_{i_{2}}$ indicates that $\mu_{i_{1} j}=\mu_{i_{2} j}$, $v_{i_{1} j}=v_{i_{2} j}$, and $\pi_{i_{1} j}=\pi_{i_{2} j}$ hold for all $c_{j} \in C$. According to (T5.2), (T6.2), and (T7.2), it is known that $r_{\mu}^{w}\left(P_{i_{1}}, P_{i_{2}}\right)=r_{\nu}^{w}\left(P_{i_{1}}, P_{i_{2}}\right)=$ $r_{\pi}^{w}\left(P_{i_{1}}, P_{i_{2}}\right)=1$, which leads to $\gamma^{w}\left(P_{i_{1}}, P_{i_{2}}\right)=1$. Namely, (T8.2) is valid. For (T8.3), by means of (T5.3), (T6.3), and (T7.3), it can be concluded that $\left|\gamma^{w}\left(P_{i_{1}}, P_{i_{2}}\right)\right| \leq 1$, i.e., (T8.3) is valid. For (T8.4), when the weight vector $\mathrm{w}=(1 / n, 1 / n, \cdots, 1 / n)$, the weighted $\mathrm{PF}$ correlation coefficient $\gamma^{w}\left(P_{i_{1}}, P_{i_{2}}\right)$ will be reduced to the PF correlation coefficient $\gamma\left(P_{i_{1}}, P_{i_{2}}\right)$ using Definition 5 and the properties in (T5.4), (T6.4), and (T7.4). This completes the proof.

\section{PROPOSED PF TOPSIS METHOD}

This section attempts to establish a novel PF TOPSIS method for addressing MCDA problems under complex PF uncertainty and identifying the ultimate priority orders of all candidate alternatives. In contrast to the distance measures commonly used in the existing TOPSIS techniques, this paper constructs new closeness measures using the proposed (weighted) PF correlation coefficients and further develops novel PF correlation-based closeness index. Figure 1 demonstrates relevant theoretical concepts of the PF TOPSIS methodology.

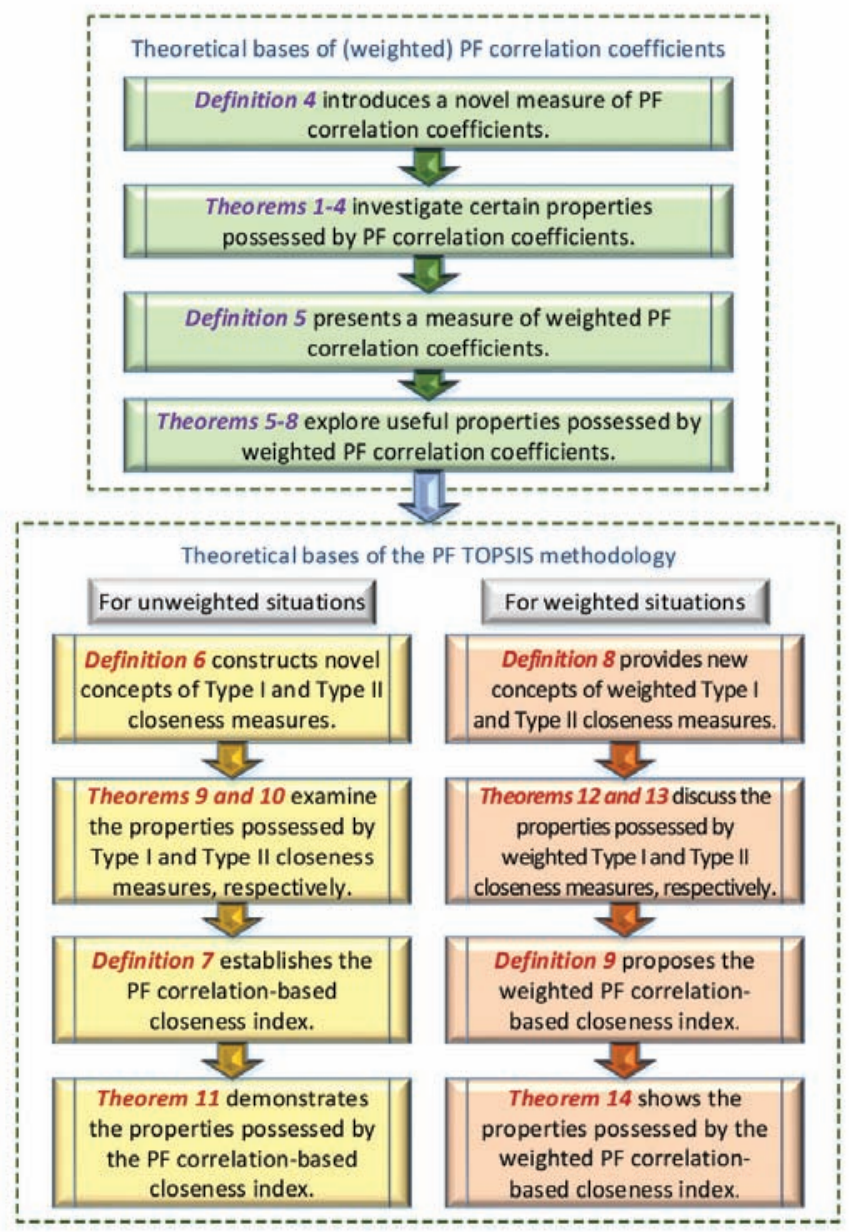

Figure 1 Theoretical bases of the proposed methodology. 
The proposed methodology is based on the principle that the best compromise alternative should have the highest positive relationship with the positive-ideal PF solution and the lowest negative relationship with the negative-ideal PF solution. To put the assertion more concretely, the developed approach starts with the determination of new closeness measures.

Definition 6. Let $P_{i}, P_{+}$, and $P_{-}$be the PF characteristics of an alternative $z_{i} \in Z$, the positive-ideal PF solution $z_{+}$, and the negativeideal PF solution $z_{-}$, respectively. Let $M_{\mathrm{I}}\left(P_{i}\right)$ and $M_{\mathrm{II}}\left(P_{i}\right)$ denote the Type I and Type II closeness measures, respectively, based on the PF correlation coefficient $\gamma$ for alternative $z_{i}$; they are defined as follows:

$$
\begin{gathered}
M_{\mathrm{I}}\left(P_{i}\right)=\frac{1-\gamma\left(P_{i}, P_{-}\right)}{2-\gamma\left(P_{i}, P_{+}\right)-\gamma\left(P_{i}, P_{-}\right)}, \\
M_{\mathrm{II}}\left(P_{i}\right)=\frac{1+\gamma\left(P_{i}, P_{+}\right)}{2+\gamma\left(P_{i}, P_{+}\right)+\gamma\left(P_{i}, P_{-}\right)} .
\end{gathered}
$$

Consider the relationships among the PF characteristics $P_{i}, P_{+}$, and $P_{-}$based on the PF correlation coefficient $\gamma$ in Definition 4. As a whole, a positive $\gamma\left(P_{i}, P_{+}\right)\left(\right.$or $\left.\gamma\left(P_{i}, P_{-}\right)\right)$represents that there is a positive association between $P_{i}$ and $P_{+}\left(\right.$or $\left.P_{-}\right)$, whereas a negative $\gamma\left(P_{i}, P_{+}\right)$(or $\left.\gamma\left(P_{i}, P_{-}\right)\right)$indicates a negative association. More specifically, the larger the $\gamma\left(P_{i}, P_{+}\right)$is, the better the PF characteristic $P_{i}$ is. In contrast, the larger the $\gamma\left(P_{i}, P_{-}\right)$is, the worse the PF characteristic $P_{i}$ is. The Type I closeness measure $M_{\mathrm{I}}\left(P_{i}\right)$ is an attempt to concretize the abovementioned choice rationale. On the other side, the smaller the $\gamma\left(P_{i}, P_{+}\right)$is, the worse the PF characteristic $P_{i}$ is; conversely, the smaller the $\gamma\left(P_{i}, P_{-}\right)$is, the better the PF characteristic $P_{i}$ is. The Type II closeness measure $M_{\mathrm{II}}\left(P_{i}\right)$ is an attempt to concretize the second choice rationale.

Theorem 9. For each $P F$ characteristic $P_{i}$ in the PF decision matrix $p$, the Type I closeness measure $M_{I}\left(P_{i}\right)$ satisfies the following properties:

- $($ T9.1 $) 0 \leq M_{I}\left(P_{i}\right) \leq 1$;

- (T9.2) $M_{I}\left(P_{i}\right)=1$ if $\gamma\left(P_{i}, P_{+}\right)=1$;

- (T9.3) $M_{I}\left(P_{i}\right)=0$ if $\gamma\left(P_{i}, P_{-}\right)=1$;

- (T9.4) $M_{I}\left(P_{-}\right)=0$ and $M_{I}\left(P_{+}\right)=1$.

Proof. For (T9.1), it is known that $-1 \leq \gamma\left(P_{i}, P_{+}\right) \leq 1$ and $-1 \leq \gamma\left(P_{i}, P_{\#}\right) \leq 1$ based on the property in (T4.3). It follows that $0 \leq 1-\gamma\left(P_{i}, P_{+}\right) \leq 2,0 \leq 1-\gamma\left(P_{i}, P_{-}\right) \leq$ 2 , and $0 \leq 2-\gamma\left(P_{i}, P_{+}\right)-\gamma\left(P_{i}, P_{-}\right) \leq 4$. Thus, the property $0 \leq M_{\mathrm{I}}\left(P_{i}\right) \leq 1$ can be readily inferred. For (T9.2), it is easily seen that the assumption $\gamma\left(P_{i}, P_{+}\right)=1$ results in $M_{\mathrm{I}}\left(P_{i}\right)=\left(1-\gamma\left(P_{i}, P_{-}\right)\right) /\left(2-1-\gamma\left(P_{i}, P_{-}\right)\right)=1$. For (T9.3), when $\gamma\left(P_{i}, P_{-}\right)=1$, it can be obtained that $M_{\mathrm{I}}\left(P_{i}\right)=$ $(1-1) /\left(2-\gamma\left(P_{i}, P_{+}\right)-1\right)=0$. For $($ T9.4 $)$, one has $\gamma\left(P_{+}, P_{+}\right)=$ 1 and $\gamma\left(P_{-}, P_{-}\right)=1$ according to (T4.2). Next, the properties $M_{\mathrm{I}}\left(P_{+}\right)=1$ and $M_{I}\left(P_{-}\right)=0$ can be evidently inferred from (T9.2) and (T9.3), respectively. This establishes the theorem.

Furthermore, let us examine the property in (T9.2). Notice that there is a perfect positive correlation between $P_{i}$ and $P_{+}$because $\gamma\left(P_{i}, P_{+}\right)=1$. The stronger the positive relationship between $P_{i}$ and $P_{+}$, the better the alternative $z_{i}$ is. It is easy to see that the
Type I closeness measure in Definition 6 generates an acceptable and desirable result, that is, $M_{\mathrm{I}}\left(P_{i}\right)=1$. Consider the property in (T9.3). One can also observe that there is a perfect positive correlation between $P_{i}$ and $P_{-}$because $\gamma\left(P_{i}, P_{-}\right)=1$. The stronger the positive relationship between $P_{i}$ and $P_{-}$, the worse the alternative $z_{i}$ is. It is clear that the Type I closeness measure in Definition 6 can produce a reasonable result, that is, $M_{\mathrm{I}}\left(P_{i}\right)=0$.

Theorem 10. For each $P F$ characteristic $P_{i}$ in the $P F$ decision matrix $p$, the Type II closeness measure $M_{I I}\left(P_{i}\right)$ satisfies the following properties:

- $(T 10.1) 0 \leq M_{I I}\left(P_{i}\right) \leq 1$;

- (T10.2) $M_{I I}\left(P_{i}\right)=0$ if $\gamma\left(P_{i}, P_{+}\right)=-1$;

- (T10.3) $M_{I I}\left(P_{i}\right)=1$ if $\gamma\left(P_{i}, P_{-}\right)=-1$;

- $(T 10.4) M_{I I}\left(P_{-}\right) \leq M_{I I}\left(P_{+}\right)$.

Proof. For (T10.1), based on $-1 \leq \gamma\left(P_{i}, P_{+}\right) \leq 1$ and $-1 \leq$ $\gamma\left(P_{i}, P_{-}\right) \leq 1$ from (T4.3), it can be easily shown that $0 \leq 1+$ $\gamma\left(P_{i}, P_{+}\right) \leq 2,0 \leq 1+\gamma\left(P_{i}, P_{-}\right) \leq 2$. It follows that $0 \leq$ $2+\gamma\left(P_{i}, P_{+}\right)+\gamma\left(P_{i}, P_{-}\right) \leq 4$. Thus, the property $0 \leq M_{\mathrm{II}}\left(P_{i}\right) \leq 1$ can be easily acquired. For (T10.2), the assumption $\gamma\left(P_{i}, P_{+}\right)=$ -1 indicates that $M_{\mathrm{II}}\left(P_{i}\right)=(1-1) /\left(2-1+\gamma\left(P_{i}, P_{-}\right)\right)=0$. For (T10.3), the assumption $\gamma\left(P_{i}, P_{-}\right)=-1$ leads to $M_{\mathrm{II}}\left(P_{i}\right)=$ $\left(1+\gamma\left(P_{i}, P_{+}\right)\right) /\left(2+\gamma\left(P_{i}, P_{+}\right)-1\right)=1$. For $(\mathrm{T} 10.4)$, based on the properties of (T4.1) and (T4.2), it is known that $\gamma\left(P_{+}, P_{-}\right)=$ $\gamma\left(P_{-}, P_{+}\right)$and $\gamma\left(P_{-}, P_{-}\right)=\gamma\left(P_{+}, P_{+}\right)=1$. By use of Definition 6, the following results can be obtained:

$$
\begin{aligned}
M_{\mathrm{II}}\left(P_{-}\right) & =\frac{1+\gamma\left(P_{-}, P_{+}\right)}{2+\gamma\left(P_{-}, P_{+}\right)+\gamma\left(P_{-}, P_{-}\right)} \\
& =\frac{1+\gamma\left(P_{-}, P_{+}\right)}{3+\gamma\left(P_{-}, P_{+}\right)}
\end{aligned}
$$

$$
\begin{aligned}
M_{\mathrm{II}}\left(P_{+}\right) & =\frac{1+\gamma\left(P_{+}, P_{+}\right)}{2+\gamma\left(P_{+}, P_{+}\right)+\gamma\left(P_{+}, P_{-}\right)} \\
& =\frac{2}{3+\gamma\left(P_{+}, P_{-}\right)}=\frac{2}{3+\gamma\left(P_{-}, P_{+}\right)}
\end{aligned}
$$

Because $\gamma\left(P_{-}, P_{+}\right) \leq 1$ according to (T4.3), it can be concluded that $M_{\mathrm{II}}\left(P_{-}\right) \leq M_{\mathrm{II}}\left(P_{+}\right)$, which establishes the theorem.

Again, let us explore the property in (T10.2). It is worth noting that there is a perfect negative correlation between $P_{i}$ and $P_{+}$in case of $\gamma\left(P_{i}, P_{+}\right)=-1$. The stronger the negative relationship between $P_{i}$ and $P_{+}$, the worse the alternative $z_{i}$ is. It can be observed that the Type II closeness measure in Definition 6 can yield a reasonable result, that is, $M_{\mathrm{II}}\left(P_{i}\right)=0$. Next, consider the property in (T10.3). There is a perfect negative correlation between $P_{i}$ and $P_{-}$because $\gamma\left(P_{i}, P_{-}\right)=-1$. The stronger the negative relationship between $P_{i}$ and $P_{-}$, the better the alternative $z_{i}$ is. Thus, it is clearly known that the Type II closeness measure in Definition 6 generates an acceptable result, that is, $M_{\mathrm{II}}\left(P_{i}\right)=1$.

It is worth stressing that both $M_{\mathrm{I}}\left(P_{i}\right)$ and $M_{\mathrm{II}}\left(P_{i}\right)$ are appropriate for the specialized situations. To acquire a balanced consequence 
in the proposed PF TOPSIS procedure, this paper provides a comprehensive measure named as the PF correlation-based closeness index to simultaneously take into account both the Type I and Type II closeness measures.

Definition 7. Let $M_{\mathrm{I}}\left(P_{i}\right)$ and $M_{\mathrm{II}}\left(P_{i}\right)$ be the Type I and Type II closeness measures, respectively, for alternative $z_{i} \in Z$. Let $\xi$ denote a closeness parameter, where $0 \leq \xi \leq 1$. The PF correlation-based closeness index $I\left(P_{i}\right)$ of alternative $z_{i}$ is defined as follows:

$$
I\left(P_{i}\right)=\xi \cdot M_{\mathrm{I}}\left(P_{i}\right)+(1-\xi) \cdot M_{\mathrm{II}}\left(P_{i}\right) .
$$

The closeness parameter $\xi$ is referred to as the influence of the Type I and Type II closeness measures. It is supposed to vary (over $0 \leq \xi \leq 1)$ according to the emphasis on either $M_{\mathrm{I}}\left(P_{i}\right)$, or $M_{\mathrm{II}}\left(P_{i}\right)$, or both. The larger $\xi$ value indicates that the specification of the PF correlation-based closeness index $I\left(P_{i}\right)$ would focus on the Type I closeness measure $M_{\mathrm{I}}\left(P_{i}\right)$. The smaller $\xi$ value means that the specification of the $I\left(P_{i}\right)$ focuses on the Type II closeness measure $M_{\mathrm{II}}\left(P_{i}\right)$. As is apparent, the extreme case $\xi=1$ produces the pure $M_{\mathrm{I}}\left(P_{i}\right)$ results, while the extreme case $\xi=0$ yields the pure $M_{\mathrm{II}}\left(P_{i}\right)$ results.

Theorem 11. For each PF characteristic $P_{i}$ in the PF decision matrix $p$, the PF correlation-based closeness index $I\left(P_{i}\right)$ satisfies the following properties:

- $(T 11.1) 0 \leq I\left(P_{i}\right) \leq 1$;

- $(T 11.2) I\left(P_{i}\right)=M_{I}\left(P_{i}\right)$ if $\xi=1$;

- (T11.3) $I\left(P_{i}\right)=M_{I I}\left(P_{i}\right)$ if $\xi=0$;

- $(T 11.4) I\left(P_{-}\right) \leq I\left(P_{+}\right)$.

Proof. (T11.1) is evident according to Definition 7 and the properties in (T9.1) and (T10.1). (T11.2) and (T11.3) are straightforward from Definition 7. For (T11.4), it is known that $M_{\mathrm{I}}\left(P_{-}\right) \leq M_{\mathrm{I}}\left(P_{+}\right)$ because $M_{\mathrm{I}}\left(P_{-}\right)=0$ and $M_{\mathrm{I}}\left(P_{+}\right)=1$ using the property in (T9.4). Moreover, one has $M_{\mathrm{II}}\left(P_{-}\right) \leq M_{\mathrm{II}}\left(P_{+}\right)$from (T10.4). It directly follows that $I\left(P_{-}\right) \leq I\left(P_{+}\right)$. This completes the proof.

Next, consider the weighted situation in which the weight vector $\mathrm{w}=\left(w_{1}, w_{2}, \cdots, w_{n}\right)$ is incorporated into the definitions of closeness measures.

Definition 8. Let $P_{i}, P_{+}$, and $P_{-}$be the PF characteristics of an alternative $z_{i} \in Z$, the positive-ideal PF solution $z_{+}$, and the negativeideal PF solution $z_{-}$, respectively. Let $w_{j}$ be the weight of criterion $c_{j} \in C$ with $w_{j} \in[0,1]$ and $\sum_{j=1}^{n} w_{j}=1$. Let $M_{\mathrm{I}}^{w}\left(P_{i}\right)$ and $M_{\mathrm{II}}^{w}\left(P_{i}\right)$ denote the weighted Type I and Type II closeness measures, respectively, based on the PF correlation coefficient $\gamma$ for alternative $z_{i}$; they are defined as follows:

$$
\begin{aligned}
& M_{I}^{w}\left(P_{i}\right)=\frac{1-\gamma^{w}\left(P_{i}, P_{-}\right)}{2-\gamma^{w}\left(P_{i}, P_{+}\right)-\gamma^{w}\left(P_{i}, P_{-}\right)}, \\
& M_{I I}^{w}\left(P_{i}\right)=\frac{1+\gamma^{w}\left(P_{i}, P_{+}\right)}{2+\gamma^{w}\left(P_{i}, P_{+}\right)+\gamma^{w}\left(P_{i}, P_{-}\right)} .
\end{aligned}
$$

Theorem 12. For each $P F$ characteristic $P_{i}$ in the $P F$ decision matrix $p$, the weighted Type I closeness measure $M_{I}^{w}\left(P_{i}\right)$ satisfies the following properties:

- $(T 12.1) 0 \leq M_{I}^{w}\left(P_{i}\right) \leq 1$;

- (T12.2) $M_{I}^{w}\left(P_{i}\right)=1$ if $\gamma^{w}\left(P_{i}, P_{+}\right)=1$;

- $(T 12.3) M_{I}^{w}\left(P_{i}\right)=0$ if $\gamma^{w}\left(P_{i}, P_{-}\right)=1$;

- $(T 12.4) M_{I}^{w}\left(P_{-}\right)=0$ and $M_{I}^{w}\left(P_{+}\right)=1$;

- $(T 12.5) M_{I}^{w}\left(P_{i}\right)=M_{I}\left(P_{i}\right)$ if $w=(1 / n, 1 / n, \cdots, 1 / n)$.

Proof. For (T12.1), by use of (T8.3), it is known that $-1 \leq \gamma^{w}\left(P_{i}, P_{+}\right) \leq 1$ and $-1 \leq \gamma^{w}\left(P_{i}, P_{\#}\right) \leq 1$. Thus, it is easily observed that $0 \leq 1-\gamma^{w}\left(P_{i}, P_{+}\right) \leq 2,0 \leq 1-\gamma^{w}\left(P_{i}, P_{-}\right) \leq 2$, and $0 \leq 2-\gamma^{w}\left(P_{i}, P_{+}\right)-\gamma^{w}\left(P_{i}, P_{-}\right) \leq 4$. As a result, the property $0 \leq M_{\mathrm{I}}^{w}\left(P_{i}\right) \leq 1$ is valid. For $(\mathrm{T} 12.2)$, when $\gamma^{w}\left(P_{i}, P_{+}\right)=1$, one has $M_{\mathrm{I}}^{w}\left(P_{i}\right)=\left(1-\gamma^{w}\left(P_{i}, P_{-}\right)\right) /\left(2-1-\gamma^{w}\left(P_{i}, P_{-}\right)\right)=1$. For (T12.3), when $\gamma^{w}\left(P_{i}, P_{-}\right)=1$, one obtains $M_{\mathrm{I}}^{w}\left(P_{i}\right)=$ $(1-1) /\left(2-\gamma^{w}\left(P_{i}, P_{+}\right)-1\right)=0$. For $(\mathrm{T} 12.4)$, because $\gamma^{w}\left(P_{+}, P_{+}\right)=1$ and $\gamma^{w}\left(P_{-}, P_{-}\right)=1$ based on (T8.2), the properties $M_{\mathrm{I}}^{w}\left(P_{+}\right)=1$ and $M_{\mathrm{I}}^{w}\left(P_{-}\right)=0$ can be acquired from (T12.2) and (T12.3), respectively. For (T12.5), when $\mathrm{w}=(1 / n, 1 / n, \cdots, 1 / n)$, it is known that $\gamma^{w}\left(P_{i}, P_{+}\right)=\gamma\left(P_{i}, P_{+}\right)$ and $\gamma^{w}\left(P_{i}, P_{-}\right)=\gamma\left(P_{i}, P_{-}\right)$based on (T8.4). Therefore, the result $M_{\mathrm{I}}^{w}\left(P_{i}\right)=M_{\mathrm{I}}\left(P_{i}\right)$ is valid. This completes the proof.

Theorem 13. For each $P F$ characteristic $P_{i}$ in the $P F$ decision matrix $p$, the weighted Type II closeness measure $M_{I I}\left(P_{i}\right)$ satisfies the following properties:

- $(T 13.1) 0 \leq M_{I I}^{w}\left(P_{i}\right) \leq 1$;

- (T13.2) $M_{I I}^{w}\left(P_{i}\right)=0$ if $\gamma^{w}\left(P_{i}, P_{+}\right)=-1$;

- (T13.3) $M_{I I}^{w}\left(P_{i}\right)=1$ if $\gamma^{w}\left(P_{i}, P_{-}\right)=-1$;

- $(T 13.4) M_{I I}^{w}\left(P_{-}\right) \leq M_{I I}^{w}\left(P_{+}\right)$;

- $(T 13.5) M_{I I}^{w}\left(P_{i}\right)=M_{I I}\left(P_{i}\right)$ if $w=(1 / n, 1 / n, \cdots, 1 / n)$.

Proof. For (T13.1), based on $-1 \leq \gamma^{w}\left(P_{i}, P_{+}\right) \leq 1$ and $-1 \leq \gamma^{w}\left(P_{i}, P_{-}\right) \leq 1$ from (T8.3), it is evident that $0 \leq 1+$ $\gamma^{w}\left(P_{i}, P_{+}\right) \leq 2,0 \leq 1+\gamma^{w}\left(P_{i}, P_{-}\right) \leq 2$, and $0 \leq 2+$ $\gamma^{w}\left(P_{i}, P_{+}\right)+\gamma^{w}\left(P_{i}, P_{-}\right) \leq 4$. It follows that the property $0 \leq$ $M_{\mathrm{II}}^{w}\left(P_{i}\right) \leq 1$ is valid. For (T13.2), the assumption $\gamma^{w}\left(P_{i}, P_{+}\right)=$ -1 results in $M_{\mathrm{II}}^{w}\left(P_{i}\right)=(1-1) /\left(2-1+\gamma^{w}\left(P_{i}, P_{-}\right)\right)=0$. For (T13.3), the assumption $\gamma^{w}\left(P_{i}, P_{-}\right)=-1$ leads to $M_{\mathrm{II}}^{w}\left(P_{i}\right)=$ $\left(1+\gamma^{w}\left(P_{i}, P_{+}\right)\right) /\left(2+\gamma^{w}\left(P_{i}, P_{+}\right)-1\right)=1$. For (T13.4), based on the properties of (T8.1) and (T8.2), it is known that $\gamma^{w}\left(P_{+}, P_{-}\right)=\gamma^{w}\left(P_{-}, P_{+}\right)$and $\gamma^{w}\left(P_{-}, P_{-}\right)=\gamma^{w}\left(P_{+}, P_{+}\right)=1$. According to Definition 8 , the following results can be obtained:

$$
\begin{aligned}
M_{\mathrm{II}}^{w}\left(P_{-}\right) & =\frac{1+\gamma^{w}\left(P_{-}, P_{+}\right)}{2+\gamma^{w}\left(P_{-}, P_{+}\right)+\gamma^{w}\left(P_{-}, P_{-}\right)} \\
& =\frac{1+\gamma^{w}\left(P_{-}, P_{+}\right)}{3+\gamma^{w}\left(P_{-}, P_{+}\right)}
\end{aligned}
$$




$$
\begin{aligned}
M_{\mathrm{II}}^{w}\left(P_{+}\right) & =\frac{1+\gamma^{w}\left(P_{+}, P_{+}\right)}{2+\gamma^{w}\left(P_{+}, P_{+}\right)+\gamma^{w}\left(P_{+}, P_{-}\right)} \\
& =\frac{2}{3+\gamma^{w}\left(P_{+}, P_{-}\right)}=\frac{2}{3+\gamma^{w}\left(P_{-}, P_{+}\right)} .
\end{aligned}
$$

Because $\gamma^{w}\left(P_{-}, P_{+}\right) \leq 1$ according to (T8.3), it can be concluded that $M_{\mathrm{II}}^{w}\left(P_{-}\right) \leq M_{\mathrm{II}}^{w}\left(P_{+}\right)$. For $(\mathrm{T} 13.5)$, when $\mathrm{w}=$ $(1 / n, 1 / n, \cdots, 1 / n)$, it is known that $\gamma^{w}\left(P_{i}, P_{+}\right)=\gamma P\left({ }_{i}, P_{+}\right)$and $\gamma^{w}\left(P_{i}, P_{-}\right)=\gamma\left(P_{i}, P_{-}\right)$based on (T8.4). It follows that $M_{\mathrm{II}}^{w}\left(P_{i}\right)=$ $M_{\text {II }}\left(P_{i}\right)$. This establishes the theorem.

Definition 9. Let $M_{\mathrm{I}}^{w}\left(P_{i}\right)$ and $M_{\mathrm{II}}^{w}\left(P_{i}\right)$ be the weighted Type I and Type II closeness measures, respectively, for alternative $z_{i} \in Z$. Let $\xi$ denote a closeness parameter, where $0 \leq \xi \leq 1$. The weighted PF correlation-based closeness index $I^{w}\left(P_{i}\right)$ of alternative $z_{i}$ is defined as follows:

$$
I^{w}\left(P_{i}\right)=\xi \cdot M_{\mathrm{I}}^{w}\left(P_{i}\right)+(1-\xi) \cdot M_{\mathrm{II}}^{w}\left(P_{i}\right) .
$$

Theorem 14. For each $P F$ characteristic $P_{i}$ in the $P F$ decision matrix $p$, the weighted PF correlation-based closeness index $I^{w}\left(P_{i}\right)$ satisfies the following properties:

- $\quad(T 14.1) 0 \leq I^{w}\left(P_{i}\right) \leq 1$;

- $\left(\right.$ T14.2) $I^{w}\left(P_{i}\right)=M_{I}^{w}\left(P_{i}\right)$ if $\xi=1$;

- $\left(\right.$ T14.3) $I^{w}\left(P_{i}\right)=M_{I I}^{w}\left(P_{i}\right)$ if $\xi=0$;

- $\left(\right.$ T14.4) $I^{w}\left(P_{-}\right) \leq I^{w}\left(P_{+}\right)$;

- $(T 14.5) I^{w}\left(P_{i}\right)=I\left(P_{i}\right)$ if $w=(1 / n, 1 / n, \cdots, 1 / n)$.

Proof. (T14.1) is evident according to Definition 9 and the properties in (T12.1) and (T13.1). (T14.2) and (T14.3) are straightforward from Definition 9. For (T14.4), it is known that $M_{\mathrm{I}}^{w}\left(P_{-}\right) \leq M_{\mathrm{I}}^{w}\left(P_{+}\right)$ because $M_{\mathrm{I}}^{w}\left(P_{-}\right)=0$ and $M_{\mathrm{I}}^{w}\left(P_{+}\right)=1$ using the property in (T12.4). Additionally, one has $M_{\mathrm{II}}^{w}\left(P_{-}\right) \leq M_{\mathrm{II}}^{w}\left(P_{+}\right)$from (T13.4). Thus, one can obtain $I^{w}\left(P_{-}\right) \leq I^{w}\left(P_{+}\right)$. For (T14.5), the result of $I^{w}\left(P_{i}\right)=I\left(P_{i}\right)$ can be inferred based on the properties in (T12.5) and (T13.5). This completes the proof.

Based on the proposed concepts of PF correlation coefficients, Type I and Type II closeness measures, and PF correlation-based closeness indices, this paper proposes a novel PF TOPSIS method for addressing MCDA problems involving PF information. Figure 2 illustrates the implementation procedure of the PF TOPSIS method.

The algorithmic procedure of the proposed PF TOPSIS methodology can be summarized as follows:

- Step 1: Formulate an MCDA problem with the set of candidate alternatives $Z=\left\{z_{1}, z_{2}, \cdots, z_{m}\right\}$ and the set of evaluative criteria $C=\left\{c_{1}, c_{2}, \cdots, c_{n}\right\}$, which is divided into $C_{\mathrm{B}}$ and $C_{\mathrm{C}}$.

- Step 2: Designate the weight vector $\mathrm{w}=\left(w_{1}, w_{2}, \cdots, w_{n}\right)$ for the $n$ evaluative criteria. Set $\mathrm{w}=(1 / n, 1 / n, \cdots, 1 / n)$ in the unweighted situation.

- Step 3: Establish the PF evaluative rating $p_{i j}$ of each alternative $z_{i} \in Z$ with respect to criterion $c_{j} \in C$.

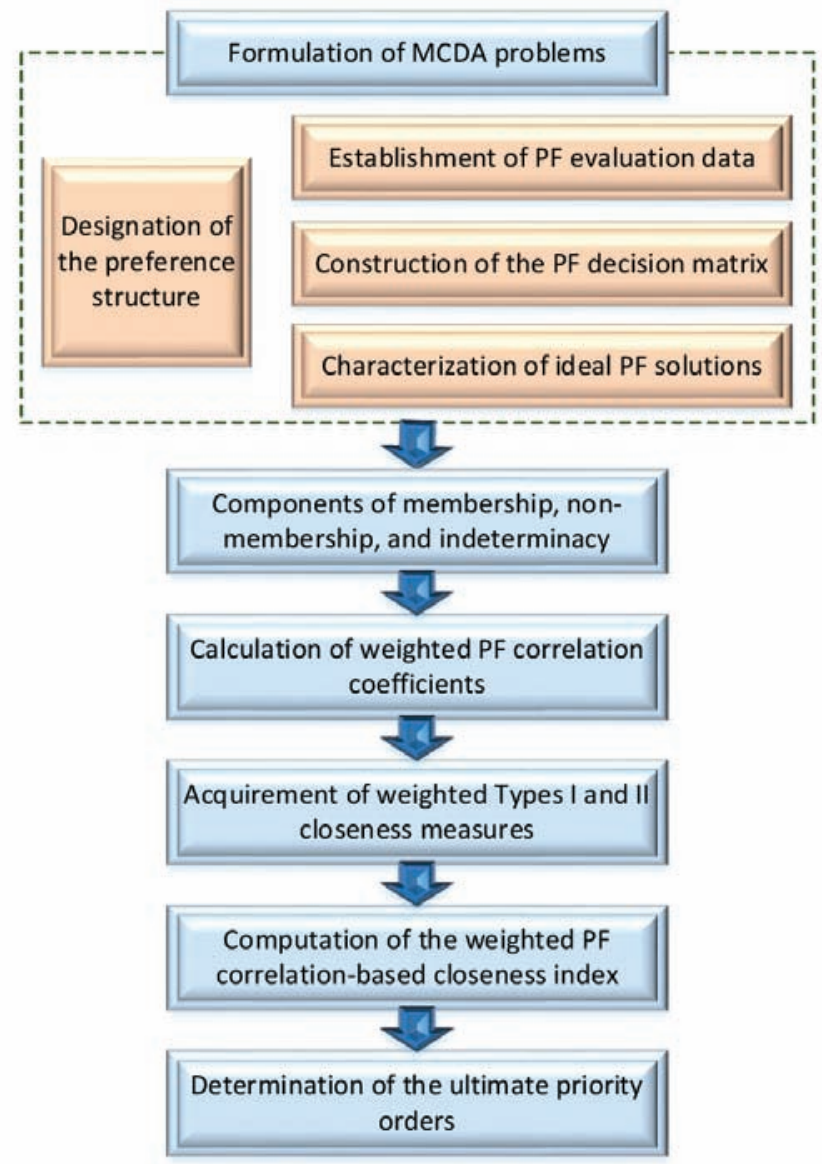

Figure 2 Algorithmic procedure of the proposed methodology.

- Step 4: Form the PF decision matrix $\mathrm{p}\left(=\left[p_{i j}\right]_{m \times n}\right)$ using Equation (10). Define the PF characteristic $P_{i}$ of each $z_{i} \in Z$ using Equation (11).

- Step 5: Identify the characteristics $P_{+}$of the positive-ideal PF solution $z_{+}$and $P_{-}$of the negative-ideal PF solution $z_{-}$using Equations (14) and (15), respectively.

- Step 6: Compute the membership components (i.e., $r_{\mu}^{w}\left(P_{i}, P_{+}\right)$ and $r_{\mu}^{w}\left(P_{i}, P_{-}\right)$, the nonmembership components (i.e., $r_{\nu}^{w}\left(P_{i}, P_{+}\right)$and $\left.r_{\nu}^{w}\left(P_{i}, P_{-}\right)\right)$, and the indeterminacy components (i.e., $r_{\pi}^{w}\left(P_{i}, P_{+}\right)$and $\left.r_{\pi}^{w}\left(P_{i}, P_{-}\right)\right)$using Equations (21-23), respectively, for each $z_{i} \in Z$.

- Step 7: Apply Equation (20) to derive the weighted PF correlation coefficients $\gamma^{w}\left(P_{i}, P_{+}\right)$and $\gamma^{w}\left(P_{i}, P_{-}\right)$between $P_{i}$ and $P_{+}$and between $P_{i}$ and $P_{-}$, respectively, for each $z_{i} \in Z$.

- Step 8: Employ Equations (27) and (28) to compute the weighted Type I closeness measure $M_{\mathrm{I}}^{w}\left(P_{i}\right)$ and the weighted Type II closeness measure $M_{\mathrm{II}}^{w}\left(P_{i}\right)$, respectively, for each $z_{i} \in Z$.

- Step 9: Set the closeness parameter $\xi$, where $0 \leq \xi \leq 1$. Calculate the weighted PF correlation-based closeness index $I^{w}\left(P_{i}\right)$ using Equation (29) for each $z_{i} \in Z$. 
- Step 10: Determine the ultimate priority orders among the $m$ alternatives according to the descending order of the $I^{w}\left(P_{i}\right)$ values.

\section{PRACTICAL APPLICATION}

This section attempts to demonstrate an illustrative application in a practical decision-making problem of hospitalization rehabilitation treatments for stroke patients with the purpose of validating the feasibility and validity of the proposed PF TOPSIS methodology. In the following, this section first describes the problem background of the medical decision concerning rehabilitation treatments for hospitalized stroke patients at acute stage.

Stroke is referred to as cerebrovascular accident. The primary cause of stroke is obstructed blood flow resulting in neurological deficits or brain hypoxia and ischemia. Stroke leads to the death or impairment of brain tissue, which may cause temporary or permanent dysfunction. According to the onset time, stroke can be divided into acute, post-acute (or sub-acute), and chronic stages. The acute stage occurs after the onset of acute stroke, and the post-acute stage occurs after patients are discharged from hospitalization for the acute phase. Finally, the chronic stage follows the post-acute stage. In particular, early rehabilitation treatment can benefit patients' recovery of walking ability, enhance their independence in daily life, and reduce length of hospital stay. Therefore, rehabilitation treatment at the acute stage in the hospital is a crucial issue for stroke patients.

Linkou Chang Gung Memorial Hospital is located in Taoyuan City, Taiwan. The hospital's total number of beds is approximately 3,700 , and the service team comprises more than 9,000 people. Annually, the hospital provides service for 4 million outpatient clinic visits, 200,000 emergency visits, and 100,000 hospitalizations. It is the largest medical institution in Taiwan. This practical application case study explored stroke rehabilitation practices and challenges in the department of nursing of Linkou Chang Gung Memorial Hospital. Using multiple criteria as stipulated by the relevant authorities, the priorities for stroke rehabilitation treatments at the acute stage were evaluated, and the findings were used as references for clinical guidelines.

The department of nursing proposed five hospitalization rehabilitation treatments (consisting of turning over $\left(z_{1}\right)$, positioning $\left(z_{2}\right)$, passive range of motion $\left(z_{3}\right)$, music rehabilitation exercise $\left(z_{4}\right)$, and air bed $\left(z_{5}\right)$ ) and eight evaluative criteria (consisting of pressure sore incidence $\left(c_{1}\right)$, aspiration pneumonia incidence $\left(c_{2}\right)$, arthrogryposis incidence $\left(c_{3}\right)$, shoulder subluxation incidence $\left(c_{4}\right)$, length of hospital stay $\left(c_{5}\right)$, degree of disability $\left(c_{6}\right)$, functional abilities for daily life $\left(c_{7}\right)$, and medical satisfaction $\left.\left(c_{8}\right)\right)$ to assess these alternatives according to patients' conditions. Because of the particularity of inpatient stroke rehabilitation, the medical decision-making problem of hospitalization rehabilitation treatments becomes a very complicated and ambiguous MCDA problem. To validate the effectiveness and practicability of the PF TOPSIS method, this paper employs the developed approach and techniques to assist the priority ranking of rehabilitation care services for hospitalized patients with stroke and cerebrovascular diseases.
In Step 1, the MCDA problem under study is defined by five hospitalization rehabilitation treatments and eight criteria for evaluating the alternatives. The set of candidate alternatives is denoted by $Z=\left\{z_{1}, z_{2}, \cdots, z_{5}\right\}$, and the set of evaluative criteria is denoted by $C=\left\{c_{1}, c_{2}, \cdots, c_{8}\right\}$, in which $C_{B}=\left\{c_{1}, c_{2}, \cdots, c_{6}\right\}$ and $C_{C}=\left\{c_{7}, c_{8}\right\}$.

In Step 2, based on the authority's knowledge and expertise in the Department of Nursing at Linkou CGMH, the weight vector for the eight evaluative criteria was designated as follows: $\mathrm{w}=(0.12,0.15$, $0.17,0.10,0.08,0.17,0.14,0.07)$. In Step 3 , the PF evaluative rating $p_{i j}$ of each alternative $z_{i} \in Z$ with respect to criterion $c_{j} \in C$ were established by the authority, as indicated in Table 1 .

Table 1 Data of the PF evaluative ratings.

\begin{tabular}{ccccc}
\hline$z_{\boldsymbol{i}}$ & $\boldsymbol{c}_{\boldsymbol{1}}$ & $\boldsymbol{c}_{\mathbf{2}}$ & $\boldsymbol{c}_{\mathbf{3}}$ & $\boldsymbol{c}_{\boldsymbol{4}}$ \\
\hline$z_{1}$ & $(0.05,0.92)$ & $(0.74,0.37)$ & $(0.51,0.46)$ & $(0.63,0.57)$ \\
$z_{2}$ & $(0.12,0.88)$ & $(0.13,0.87)$ & $(0.25,0.76)$ & $(0.49,0.64)$ \\
$z_{3}$ & $(0.74,0.30)$ & $(0.98,0.00)$ & $(0.13,0.87)$ & $(0.37,0.73)$ \\
$z_{4}$ & $(0.87,0.24)$ & $(0.99,0.00)$ & $(0.12,0.82)$ & $(0.36,0.66)$ \\
$z_{5}$ & $(0.01,0.97)$ & $(0.98,0.00)$ & $(0.86,0.16)$ & $(0.99,0.01)$ \\
& $\mathbf{c}_{\mathbf{5}}$ & $\mathbf{c}_{\mathbf{6}}$ & $\mathbf{c}_{\mathbf{7}}$ & $\mathbf{c}_{\mathbf{8}}$ \\
$z_{1}$ & $(0.38,0.81)$ & $(0.99,0.00)$ & $(0.13,0.93)$ & $(0.38,0.68)$ \\
$z_{2}$ & $(0.76,0.39)$ & $(0.63,0.60)$ & $(0.38,0.68)$ & $(0.37,0.85)$ \\
$z_{3}$ & $(0.26,0.71)$ & $(0.48,0.56)$ & $(0.52,0.51)$ & $(0.53,0.55)$ \\
$z_{4}$ & $(0.24,0.89)$ & $(0.49,0.57)$ & $(0.51,0.71)$ & $(0.65,0.32)$ \\
$z_{5}$ & $(0.35,0.84)$ & $(0.85,0.11)$ & $(0.13,0.86)$ & $(0.88,0.21)$ \\
\hline
\end{tabular}

In Step 4, the PF decision matrix was constructed based on the PF evaluative ratings in Table 1 , that is, $p=$ $\left[p_{i j}\right]_{5 \times 8}=\left[\left(\mu_{i j}, v_{i j}\right)\right]_{5 \times 8}$. The PF characteristic $P_{i}$ of each $z_{i}$ was identified $P_{i}=\left\{\left\langle c_{1}, p_{i 1}\right\rangle,\left\langle c_{2}, p_{i 2}\right\rangle, \cdots,\left\langle c_{8}, p_{i 8}\right\rangle\right\}=$ $\left\{\left\langle c_{1},\left(\mu_{i 1}, v_{i 1}\right)\right\rangle,\left\langle c_{2},\left(\mu_{i 2}, v_{i 2}\right)\right\rangle, \cdots,\left\langle c_{8},\left(\mu_{i 8}, v_{i 8}\right)\right\rangle\right\}$.

In Step 5 , the characteristics $P_{+}$and $P_{-}$of the positive- and negativeideal PF solutions $z_{+}$and $z_{-}$, respectively, were obtained as follows:

$$
\begin{aligned}
P_{+}= & \left\{\left\langle c_{1}, p_{+1}\right\rangle,\left\langle c_{2}, p_{+2}\right\rangle, \cdots,\left\langle c_{8}, p_{+8}\right\rangle\right\} \\
& \left\{\left\langle c_{1},(0.01,0.97)\right\rangle,\left\langle c_{2},(0.13,0.87)\right\rangle,\left\langle c_{3},(0.12,0.87)\right\rangle,\right. \\
= & \left\langle c_{4},(0.36,0.73)\right\rangle,\left\langle c_{5},(0.24,0.89)\right\rangle,\left\langle c_{6},(0.48,0.60)\right\rangle, \\
& \left.\left\langle c_{7},(0.52,0.51)\right\rangle,\left\langle c_{8},(0.88,0.21)\right\rangle\right\}, \\
& \\
P_{-}= & \left\{\left\langle c_{1}, p_{-1}\right\rangle,\left\langle c_{2}, p_{-2}\right\rangle, \cdots,\left\langle c_{8}, p_{-8}\right\rangle\right\} \\
& \left\{\left\langle c_{1},(0.87,0.24)\right\rangle,\left\langle c_{2},(0.99,0.00)\right\rangle,\left\langle c_{3},(0.86,0.16)\right\rangle,\right. \\
= & \left\langle c_{4},(0.99,0.01)\right\rangle,\left\langle c_{5},(0.76,0.39)\right\rangle,\left\langle c_{6},(0.99,0.00)\right\rangle, \\
& \left.\left\langle c_{7},(0.13,0.93)\right\rangle,\left\langle c_{8},(0.37,0.85)\right\rangle\right\} .
\end{aligned}
$$

In Step 6, the membership, nonmembership, and indeterminacy components of the weighted PF correlation coefficients between $P_{i}$ and $P_{+}$and between $P_{i}$ and $P_{-}$were derived for each $z_{i} \in Z$. The computation results of $r_{\mu}^{w}\left(P_{i}, P_{+}\right), r_{\nu}^{w}\left(P_{i}, P_{+}\right), r_{\pi}^{w}\left(P_{i}, P_{+}\right)$, $r_{\mu}^{w}\left(P_{i}, P_{-}\right), r_{\nu}^{w}\left(P_{i}, P_{-}\right)$, and $r_{\pi}^{w}\left(P_{i}, P_{-}\right)$are revealed in Table 2. In Step 7 , based on the obtained components, the determination results of $\gamma^{w}\left(P_{i}, P_{+}\right)$and $\gamma^{w}\left(P_{i}, P_{-}\right)$for each $z_{i}$ are presented in Table 2 as well. In Step 8, the weighted Type I closeness measures for each $z_{i}$ were calculated as follows: $M_{\mathrm{I}}^{w}\left(P_{1}\right)=0.3664, M_{\mathrm{I}}^{w}\left(P_{2}\right)=0.6109$, 
Table 2 Results of the weighted PF correlation coefficients.

\begin{tabular}{ccccc}
\hline$z_{\boldsymbol{i}}$ & $\mathbf{r}_{\mu}^{\mathbf{w}}\left(\mathbf{P}_{\mathbf{i}}, \mathbf{P}_{+}\right)$ & $\mathbf{r}_{\nu}^{\mathbf{w}}\left(\mathbf{P}_{\mathbf{i}}, \mathbf{P}_{+}\right)$ & $\mathbf{r}_{\pi}^{\mathbf{w}}\left(\mathbf{P}_{\mathbf{i}}, \mathbf{P}_{+}\right)$ & $\gamma^{\mathbf{w}}\left(\mathbf{P}_{\mathbf{i}}, \mathbf{P}_{+}\right)$ \\
\hline$z_{1}$ & -0.4106 & 0.0553 & -0.4457 & -0.2670 \\
$z_{2}$ & 0.6241 & 0.7283 & 0.5484 & 0.6336 \\
$z_{3}$ & -0.2604 & 0.2067 & 0.3604 & 0.1022 \\
$z_{4}$ & -0.2237 & 0.1228 & 0.2256 & 0.0416 \\
$z_{5}$ & -0.4605 & -0.1008 & 0.0895 & -0.1572 \\
& $\mathbf{r}_{\mu}^{\mathbf{w}}\left(\mathbf{P}_{\mathbf{i}}, \mathbf{P}_{-}\right)$ & $\mathbf{r}_{\nu}^{\mathbf{w}}\left(\mathbf{P}_{\mathbf{i}}, \mathbf{P}_{-}\right)$ & $\mathbf{r}_{\pi}^{\mathbf{w}}\left(\mathbf{P}_{\mathbf{i}}, \mathbf{P}_{-}\right)$ & $\gamma^{\mathbf{w}}\left(\mathbf{P}_{\mathbf{i}}, \mathbf{P}_{-}\right)$ \\
$z_{1}$ & 0.4694 & 0.1351 & 0.1971 & 0.2672 \\
$z_{2}$ & -0.3628 & -0.1924 & -0.3491 & -0.3015 \\
$z_{3}$ & 0.0300 & -0.3781 & -0.5710 & -0.3064 \\
$z_{4}$ & 0.1275 & -0.3553 & -0.6878 & -0.3052 \\
$z_{5}$ & 0.6956 & 0.0629 & 0.5537 & 0.4374 \\
\hline
\end{tabular}

PF, Pythagorean fuzzy.

$M_{\mathrm{I}}^{w}\left(P_{3}\right)=0.6403, M_{\mathrm{I}}^{w}\left(P_{4}\right)=0.6262$, and $M_{\mathrm{I}}^{w}\left(P_{5}\right)=0.4425$. The weighted Type II closeness measures were computed as follows: $M_{\mathrm{II}}^{w}\left(P_{1}\right)=0.3665, M_{\mathrm{II}}^{w}\left(P_{2}\right)=0.6263, M_{\mathrm{II}}^{w}\left(P_{3}\right)=0.6461$, $M_{\mathrm{II}}^{w}\left(P_{4}\right)=0.6373$, and $M_{\mathrm{II}}^{w}\left(P_{5}\right)=0.4732$.

In Step 9, the closeness parameter was designated as follows: $\xi=$ 0.5 . Next, the weighted PF correlation-based closeness indices were acquired as follows: $I^{w}\left(P_{1}\right)=0.3665, I^{w}\left(P_{2}\right)=0.6186, I^{w}\left(P_{3}\right)=$ $0.6432, I^{w}\left(P_{4}\right)=0.6318$, and $I^{w}\left(P_{5}\right)=0.4578$. In Step 10, based on the descending order of these $I^{w}\left(P_{i}\right)$ values, the ultimate priority ranking $z_{3}>z_{4}>z_{2}>z_{5}>z_{1}$ was obtained as a useful decisionaiding suggestion for the MCDA problem of hospitalization rehabilitation treatments.

Furthermore, more comparative discussions of the determination results are conducted to examine the effectiveness and reasonability of the practical application. Concerning the rehabilitation treatment case, some comprehensive comparisons are depicted in Figures 3 and 4 . In regard to each $z_{i} \in Z$, the contrasts of the weighted Type I closeness measure $M_{\mathrm{I}}^{w}\left(P_{i}\right)$, the weighted Type II closeness measure $M_{\mathrm{II}}^{w}\left(P_{i}\right)$, and the weighted PF correlation-based closeness index $I^{w}\left(P_{i}\right)$ are presented in Figure 3. The obtained $M_{\mathrm{I}}^{w}\left(P_{i}\right)$ and $M_{\mathrm{II}}^{w}\left(P_{i}\right)$ are very close with respect to each alternative, especially for the alternatives $z_{2}, z_{3}$, and $z_{4}$. More precisely, the absolute differences between $M_{\mathrm{I}}^{w}\left(P_{i}\right)$ and $M_{\mathrm{II}}^{w}\left(P_{i}\right)$ for each alternative were acquired as follows: 0.0001 for $z_{1}, 0.0154$ for $z_{2}, 0.0058$ for $z_{3}, 0.0111$ for $z_{4}$, and 0.0307 for $z_{5}$. The distribution patterns of $M_{\mathrm{I}}^{w}\left(P_{i}\right)$ and $M_{\mathrm{II}}^{w}\left(P_{i}\right)$ are very similar concerning all of the five alternatives. Accordingly, the general pattern of $I^{w}\left(P_{i}\right)$ across all alternatives is concordant with the respective findings based on $M_{\mathrm{I}}^{w}\left(P_{i}\right)$ and $M_{\mathrm{II}}^{w}\left(P_{i}\right)$, as demonstrated in Figure 3.

Based on the descending orders of the $M_{\mathrm{I}}^{w}\left(P_{i}\right), M_{\mathrm{II}}^{w}\left(P_{i}\right)$, and $I^{w}\left(P_{i}\right)$ values, three priority ranking orders of alternatives are contrasted in Figure 4. The consistent results can be found in terms of the priority orders of the five candidate alternatives. More specifically, the priority ranking is given as $z_{3}>z_{4}>z_{2}>z_{5}>z_{1}$ regardless of the comparison bases of $M_{\mathrm{I}}^{w}\left(P_{i}\right), M_{\mathrm{II}}^{w}\left(P_{i}\right)$, and $I^{w}\left(P_{i}\right)$. Because the priority ranking orders are in line with each other, the stability of the results is all the more impressive.

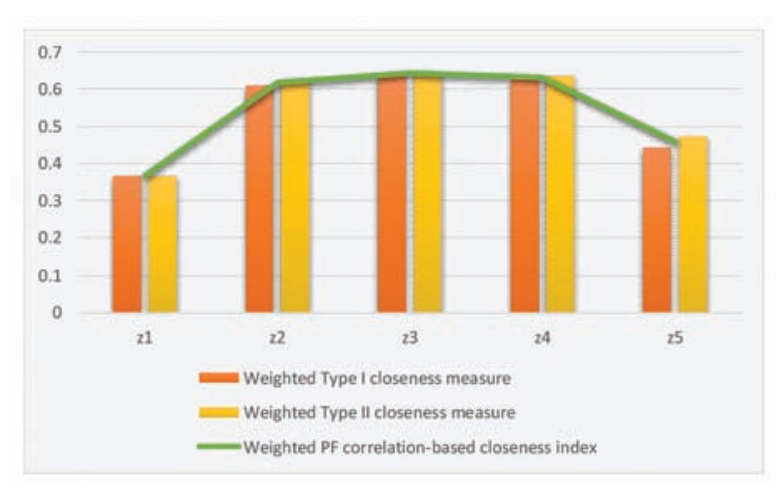

Figure 3 Comparison of closeness measures and PF correlation-based closeness indices.

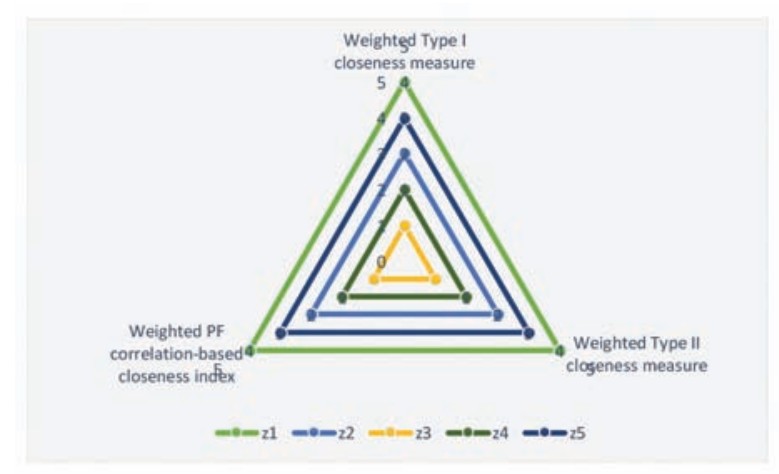

Figure 4 Contrast of the priority ranking orders of alternatives via $M_{\mathrm{I}}^{w}\left(P_{i}\right), M_{\mathrm{II}}^{w}\left(P_{i}\right)$, and $I^{w}\left(P_{i}\right)$.

\section{COMPARATIVE STUDIES}

This section conducts some comparative analyses with previous researches to validate the effectiveness of the proposed approach and highlight the merits of the study.

It has to be stressed that the proposed PF TOPSIS method differs considerably from the existing TOPSIS techniques by its identification of relative closeness. As opposed to the current distancebased closeness indices, the proposed methodology employs novel concepts of PF correlations and two types of closeness measures to present the correlation-based closeness index, which is significantly different from the previous studies. Therefore, the comparative studies focus on the contrast of the obtained TOPSIS solutions based on correlation-based and distance-based closeness indices.

The comparative analyses investigate four TOPSIS techniques, consisting of the PF TOPSIS and traditional TOPSIS methods based on weighted evaluative ratings or weighted distances. As mentioned before, the current PF TOPSIS techniques presented by Gul and Ak [34], Liang and $\mathrm{Xu}$ [33], Liang et al. [35], Zeng et al. [32], Zhang and $\mathrm{Xu}$ [22], and Zhou et al. [36] employed PF distances as a separation measure to define relevant concepts of closeness indices. Referring the common TOPSIS structure based on distance-based closeness indices in these researches, this paper provides two PF TOPSIS 
techniques using different weighted approaches (i.e., weighted evaluative ratings and weighted distances). On the other hand, to examine the contributions and the advantages of the proposed methodology relative to the traditional TOPSIS methods, this paper converts $\mathrm{PF}$ evaluative ratings into crisp data via the normalized score functions. Analogously, this paper presents two traditional TOPSIS techniques based on weighted evaluative ratings and weighted distances.

The first comparative approach is the PF TOPSIS technique based on weighted evaluative ratings. For each $p_{i j}\left(=\left(\mu_{i j}, \nu_{i j}\right)\right)$ in the $\mathrm{PF}$ decision matrix $\mathrm{p}$, the weighted $\mathrm{PF}$ evaluative rating $p_{i j}^{w}\left(=\left(\mu_{i j}^{w}, v_{i j}^{w}\right)\right)$ is computed as follows:

$$
p_{i j}^{w}=w_{j} \cdot p_{i j}=\left(\sqrt{1-\left(1-\left(\mu_{i j}\right)^{2}\right)^{w_{j}}},\left(\nu_{i j}\right)^{w_{j}}\right) .
$$

The weighted PF characteristic $P_{i}^{w}$ is given by:

$$
P_{i}^{w}=\left\{\left\langle c_{1}, p_{i 1}^{w}\right\rangle,\left\langle c_{2}, p_{i 2}^{w}\right\rangle, \cdots,\left\langle c_{n}, p_{i n}^{w}\right\rangle\right\} .
$$

Let $z_{+}^{w}$ and $z_{-}^{w}$ denote the weighted positive- and negative-ideal PF solutions, respectively. The PF characteristics of $z_{+}^{w}$ and $z_{-}^{w}$ are represented as follows:

$$
\begin{aligned}
& P_{+}^{w}=\left\{\left\langle c_{1}, p_{+1}^{w}\right\rangle,\left\langle c_{2}, p_{+2}^{w}\right\rangle, \cdots,\left\langle c_{n}, p_{+n}^{w}\right\rangle,\right. \\
& P_{-}^{w}=\left\{\left\langle c_{1}, p_{-1}^{w}\right\rangle,\left\langle c_{2}, p_{-2}^{w}\right\rangle, \cdots,\left\langle c_{n}, p_{-n}^{w}\right\rangle\right\},
\end{aligned}
$$

where the weighted positive- and negative-ideal PF values within $P_{+}^{w}\left(=\left(\mu_{+j}^{w}, \nu_{+j}^{w}\right)\right)$ and $P_{-}^{w}\left(=\left(\mu_{-j}^{w}, \nu_{-j}^{w}\right)\right)$ are defined as follows:

$$
\begin{aligned}
& p_{+j}^{w}= \begin{cases}\underset{i=1}{\vee} p_{i j}^{w}=\left(\begin{array}{l}
m \\
\max _{i=1}^{m} \mu_{i j}^{w}, \min _{i=1}^{m} \nu_{i j}^{w}
\end{array}\right) & \text { if } \quad c_{j} \in C_{\mathrm{B}}, \\
\bigwedge_{i=1}^{m} p_{i j}^{w}=\left(\begin{array}{c}
m \\
\min _{i=1} \mu_{i j}^{w}, \max _{i=1}^{m} \nu_{i j}^{w}
\end{array}\right) & \text { if } \quad c_{j} \in C_{\mathrm{C}},\end{cases} \\
& p_{-j}^{w}= \begin{cases}\bigwedge_{i=1}^{m} p_{i j}^{w}=\left(\begin{array}{l}
m \\
\min _{i=1} \mu_{i j}^{w}, \max _{i=1}^{m} \nu_{i j}^{w}
\end{array}\right) & \text { if } \quad c_{j} \in C_{\mathrm{B}}, \\
\underset{i=1}{m} p_{i j}^{w}=\left(\begin{array}{ll}
m \\
\max _{i=1} \mu_{i j}^{w}, \min _{i=1}^{m} \nu_{i j}^{w}
\end{array}\right) & \text { if } \quad c_{j} \in C_{\mathrm{C}} .\end{cases}
\end{aligned}
$$

Based on Zhang and Xu's PF distance measure [22], the normalized distances between $P_{i}^{w}$ and $P_{+}^{w}$ as well as between $P_{i}^{w}$ and $P_{-}^{w}$ are as follows:

$$
\begin{aligned}
D\left(P_{i}^{w}, P_{+}^{w}\right)= & \frac{1}{2 n} \cdot \sum_{j=1}^{n}\left(\left|\left(\mu_{i j}^{w}\right)^{2}-\left(\mu_{+j}^{w}\right)^{2}\right|\right. \\
& \left.+\left|\left(\nu_{i j}^{w}\right)^{2}-\left(\nu_{+j}^{w}\right)^{2}\right|+\left|\left(\pi_{i j}^{w}\right)^{2}-\left(\pi_{+j}^{w}\right)^{2}\right|\right), \\
D\left(P_{i}^{w}, P_{-}^{w}\right)= & \frac{1}{2 n} \cdot \sum_{j=1}^{n}\left(\left|\left(\mu_{i j}^{w}\right)^{2}-\left(\mu_{-j}^{w}\right)^{2}\right|\right. \\
& \left.+\left|\left(\nu_{i j}^{w}\right)^{2}-\left(\nu_{-j}^{w}\right)^{2}\right|+\left|\left(\pi_{i j}^{w}\right)^{2}-\left(\pi_{-j}^{w}\right)^{2}\right|\right) .
\end{aligned}
$$

Employing the first comparative approach, the closeness coefficient $C C\left(P_{i}^{w}\right)$ of alternative $z_{i}$ is defined as follows:

$$
C C\left(P_{i}^{w}\right)=\frac{D\left(P_{i}^{w}, P_{-}^{w}\right)}{D\left(P_{i}^{w}, P_{+}^{w}\right)+D\left(P_{i}^{w}, P_{-}^{w}\right)} .
$$

The second comparative approach is the PF TOPSIS technique based on weighted distances. The normalized weighted PF distances between $P_{i}$ and $P_{+}$as well as between $P_{i}$ and $P_{-}$are calculated as follows:

$$
\begin{aligned}
D^{w}\left(P_{i}, P_{+}\right)= & \frac{1}{2 n} \cdot \sum_{j=1}^{n} w_{j} \cdot\left(\left|\left(\mu_{i j}\right)^{2}-\left(\mu_{+j}\right)^{2}\right|\right. \\
& \left.+\left|\left(\nu_{i j}\right)^{2}-\left(\nu_{+j}\right)^{2}\right|+\left|\left(\pi_{i j}\right)^{2}-\left(\pi_{+j}\right)^{2}\right|\right), \\
D^{w}\left(P_{i}, P_{-}\right)= & \frac{1}{2 n} \cdot \sum_{j=1}^{n} w_{j} \cdot\left(\left|\left(\mu_{i j}\right)^{2}-\left(\mu_{-j}\right)^{2}\right|\right. \\
& \left.+\left|\left(\nu_{i j}\right)^{2}-\left(\nu_{-j}\right)^{2}\right|+\left|\left(\pi_{i j}\right)^{2}-\left(\pi_{-j}\right)^{2}\right|\right) .
\end{aligned}
$$

Employing the second comparative approach, the closeness coefficient $C C^{w}\left(P_{i}\right)$ of alternative $z_{i}$ is defined as follows:

$$
C C^{w}\left(P_{i}\right)=\frac{D^{w}\left(P_{i}, P_{-}\right)}{D^{w}\left(P_{i}, P_{+}\right)+D^{w}\left(P_{i}, P_{-}\right)} .
$$

The third comparative approach is the traditional TOPSIS technique based on weighted evaluative ratings. Zhang and Xu's developed a score function [22] for PF values and applied it to compare the magnitudes of PF values. By modifying their definition, this paper converts the PF data into crisp numbers using the normalized outcomes of score functions. Let $\bar{p}_{i j}^{w}$ denote the weighted evaluative rating of an alternative $z_{i} \in Z$ with respect to criterion $c_{j} \in C$. It is noted that $\bar{p}_{i j}^{w}$ is expressed as a crisp number and can be determined by use of the normalized score function. For each $p_{i j}^{w}$, the weighted evaluative rating $\bar{p}_{i j}^{w}$ is acquired by the normalized score function as follows:

$$
\begin{aligned}
\bar{p}_{i j}^{w} & =\frac{1+\left(\mu_{i j}^{w}\right)^{2}-\left(\nu_{i j}^{w}\right)^{2}}{2} \\
& =\frac{2-\left(1-\left(\mu_{i j}\right)^{2}\right)^{w_{j}}-\left(\nu_{i j}\right)^{2 w_{j}}}{2} .
\end{aligned}
$$

The weighted characteristic $\bar{P}_{i}^{w}$ is given by:

$$
\bar{P}_{i}^{w}=\left\{\left\langle c_{1}, \bar{p}_{i 1}^{w}\right\rangle,\left\langle c_{2}, \bar{p}_{i 2}^{w}\right\rangle, \cdots,\left\langle c_{n}, \bar{p}_{i n}^{w}\right\rangle\right\} .
$$

The characteristics of the weighted positive- and negative-ideal solutions $\bar{z}_{+}^{w}$ and $\bar{z}_{-}^{w}$ are represented as follows:

$$
\begin{aligned}
& \bar{P}_{+}^{w}=\left\{\left\langle c_{1}, \bar{p}_{+1}^{w}\right\rangle,\left\langle c_{2}, \bar{p}_{+2}^{w}\right\rangle, \cdots,\left\langle c_{n}, \bar{p}_{+n}^{w}\right\rangle\right\}, \\
& \bar{P}_{-}^{w}=\left\{\left\langle c_{1}, \bar{p}_{-1}^{w}\right\rangle,\left\langle c_{2}, \bar{p}_{-2}^{w}\right\rangle, \cdots,\left\langle c_{n}, \bar{p}_{-n}^{w}\right\rangle\right\},
\end{aligned}
$$

where the weighted positive- and negative-ideal values within $\bar{P}_{+}^{w}$ and $\bar{P}_{-}^{w}$ are defined as follows:

$$
\bar{p}_{+j}^{w}=\left\{\begin{array}{lll}
\max _{i=1}^{m} \bar{p}_{i j}^{w} & \text { if } & c_{j} \in C_{\mathrm{B}}, \\
\min _{i=1}^{m} \bar{p}_{i j}^{w} & \text { if } & c_{j} \in C_{\mathrm{C}},
\end{array}\right.
$$




$$
\bar{p}_{-j}^{w}=\left\{\begin{array}{lll}
\min _{i=1}^{m} \bar{p}_{i j}^{w} & \text { if } & c_{j} \in C_{\mathrm{B}}, \\
\max _{i=1}^{m} \bar{p}_{i j}^{w} & \text { if } & c_{j} \in C_{\mathrm{C}} .
\end{array}\right.
$$

Based on the Hamming distance model, the closeness coefficient CC $\left(\bar{P}_{i}^{w}\right)$ of alternative $z_{i}$ is defined as follows:

$$
C C\left(\bar{P}_{i}^{w}\right)=\frac{\sum_{j=1}^{n}\left|\bar{p}_{i j}^{w}-\bar{p}_{-j}^{w}\right|}{\sum_{j=1}^{n}\left(\left|\bar{p}_{i j}^{w}-\bar{p}_{+j}^{w}\right|+\left|\bar{p}_{i j}^{w}-\bar{p}_{-j}^{w}\right|\right)} .
$$

The fourth comparative approach is the traditional TOPSIS technique based on weighted distances. Let $\bar{p}_{i j}$ denote the evaluative rating of an alternative $z_{i} \in Z$ with respect to criterion $c_{j} \in C$; it is defined as follows:

$$
\bar{p}_{i j}=\frac{1+\left(\mu_{i j}\right)^{2}-\left(\nu_{i j}\right)^{2}}{2} .
$$

The characteristic $\bar{P}_{i}$ is given by:

$$
\bar{P}_{i}=\left\{\left\langle c_{1}, \bar{p}_{i 1}\right\rangle,\left\langle c_{2}, \bar{p}_{i 2}\right\rangle, \cdots,\left\langle c_{n}, \bar{p}_{i n}\right\rangle\right\}
$$

The characteristics of the positive- and negative-ideal solutions $\bar{z}_{+}$ and $\bar{z}_{-}$are represented as follows:

$$
\begin{aligned}
& \bar{P}_{+}=\left\{\left\langle c_{1}, \bar{p}_{+1}\right\rangle,\left\langle c_{2}, \bar{p}_{+2}\right\rangle, \cdots,\left\langle c_{n}, \bar{p}_{+n}\right\rangle\right\}, \\
& \bar{P}_{-}=\left\{\left\langle c_{1}, \bar{p}_{-1}\right\rangle,\left\langle c_{2}, \bar{p}_{-2}\right\rangle, \cdots,\left\langle c_{n}, \bar{p}_{-n}\right\rangle\right\},
\end{aligned}
$$

where the positive- and negative-ideal values within $\bar{P}_{+}$and $\bar{P}_{-}$are defined as follows:

$$
\begin{aligned}
& \bar{p}_{+j}=\left\{\begin{array}{lll}
\max _{i=1}^{m} \bar{p}_{i j} & \text { if } & c_{j} \in C_{\mathrm{B}}, \\
\min _{i=1} \bar{p}_{i j} & \text { if } & c_{j} \in C_{\mathrm{C}},
\end{array}\right. \\
& \bar{p}_{-j}=\left\{\begin{array}{lll}
\min _{i=1}^{m} \bar{p}_{i j} & \text { if } & c_{j} \in C_{\mathrm{B}}, \\
m \\
\max _{i=1} \bar{p}_{i j} & \text { if } & c_{j} \in C_{\mathrm{C}} .
\end{array}\right.
\end{aligned}
$$

Based on the weighted Hamming distance model, the closeness coefficient $C C^{w}\left(\bar{P}_{i}\right)$ of alternative $z_{i}$ is defined as follows:

$$
C C^{w}\left(\bar{P}_{i}\right)=\frac{\sum_{j=1}^{n} w_{j} \cdot\left|\bar{p}_{i j}-\bar{p}_{-j}\right|}{\sum_{j=1}^{n} w_{j} \cdot\left(\left|\bar{p}_{i j}-\bar{p}_{+j}\right|+\left|\bar{p}_{i j}-\bar{p}_{-j}\right|\right)} .
$$

Consider the rehabilitation treatment case. This paper conducts the comparison of the application results rendered by the proposed methodology and the four comparative approaches within the PF uncertain and certain environments. Table 3 indicates the obtained results, consisting of the closeness coefficients $C C\left(P_{i}^{w}\right)$ and $C C^{w}\left(P_{i}\right)$ yielded by the PF TOPSIS methods based on weighted evaluative ratings and based on weighted distances, respectively, the closeness coefficients $C C\left(\bar{P}_{i}^{w}\right)$ and $C C^{w}\left(\bar{P}_{i}\right)$ produced by the traditional TOPSIS methods based on weighted evaluative ratings and based on weighted distances, respectively, and the weighted PF correlation-based closeness index $I^{w}\left(P_{i}\right)$ generated by the proposed PF TOPSIS methodology. It is noted that the obtained $C C\left(P_{i}^{w}\right)$, $C C^{w}\left(P_{i}\right)$, and $I^{w}\left(P_{i}\right)$ result from $\mathrm{PF}$ uncertain information, while $C C\left(\bar{P}_{i}^{w}\right)$ and $C C^{w}\left(\bar{P}_{i}\right)$ result from certain information.

Furthermore, a comprehensive contrast on the features and core concepts possessed by the five comparative methods is demonstrated in Table 4 . The first and second comparative approaches belong to the distance-based PF TOPSIS model; moreover, the third and fourth comparative approaches belong to the distance-based traditional TOPSIS model. In contrast, the proposed methodology

\begin{tabular}{|c|c|c|c|c|}
\hline \multicolumn{2}{|c|}{$\begin{array}{l}\text { Distance-Based } \\
\text { PF TOPSIS }\end{array}$} & \multicolumn{2}{|c|}{$\begin{array}{l}\text { Distance-Based } \\
\text { traditional TOPSIS }\end{array}$} & $\begin{array}{l}\text { Correlation- } \\
\text { Based PF } \\
\text { TOPSIS }\end{array}$ \\
\hline \multicolumn{5}{|c|}{ Comparative approach } \\
\hline $\begin{array}{l}\text { PF TOPSIS } \\
\text { based on } \\
\text { weighted } \\
\text { evaluative } \\
\text { ratings }\end{array}$ & $\begin{array}{l}\text { PF TOPSIS } \\
\text { based on } \\
\text { weighted } \\
\text { distances }\end{array}$ & $\begin{array}{l}\text { Traditional } \\
\text { TOPSIS } \\
\text { based on } \\
\text { weighted } \\
\text { evaluative } \\
\text { ratings }\end{array}$ & $\begin{array}{l}\text { Traditional } \\
\text { TOPSIS } \\
\text { based on } \\
\text { weighted } \\
\text { distances }\end{array}$ & $\begin{array}{l}\text { Proposed PF } \\
\text { TOPSIS } \\
\text { methodol- } \\
\text { ogy }\end{array}$ \\
\hline \multicolumn{5}{|c|}{ Decision environment } \\
\hline $\begin{array}{l}\text { PF context } \\
\text { Separation m }\end{array}$ & $\begin{array}{l}\text { PF context } \\
\text { asure }\end{array}$ & $\begin{array}{l}\text { Certain } \\
\text { context }\end{array}$ & $\begin{array}{l}\text { Certain } \\
\text { context }\end{array}$ & PF context \\
\hline PF distance & $\begin{array}{l}\text { Weighted PF } \\
\text { distance }\end{array}$ & $\begin{array}{l}\text { Hamming } \\
\text { distance }\end{array}$ & $\begin{array}{l}\text { Weighted } \\
\text { Hamming } \\
\text { distance }\end{array}$ & $\begin{array}{l}\text { Weighted PF } \\
\text { correlation } \\
\text { coefficient }\end{array}$ \\
\hline \multicolumn{5}{|l|}{ Key index } \\
\hline $\begin{array}{l}\text { PF distance- } \\
\text { based } \\
\text { closeness } \\
\text { index }\end{array}$ & $\begin{array}{l}\text { PF distance- } \\
\text { based } \\
\text { closeness } \\
\text { index }\end{array}$ & $\begin{array}{l}\text { Distance- } \\
\text { based } \\
\text { closeness } \\
\text { index }\end{array}$ & $\begin{array}{l}\text { Distance- } \\
\text { based } \\
\text { closeness } \\
\text { index }\end{array}$ & $\begin{array}{l}\text { Types I \& II } \\
\text { closeness } \\
\text { measures PF } \\
\text { correlation- } \\
\text { based } \\
\text { closeness } \\
\text { index }\end{array}$ \\
\hline
\end{tabular}
belongs to the correlation-based PF TOPSIS model.

To provide a better view of the comparison results, this paper puts the obtained $C C\left(P_{i}^{w}\right), C C^{w}\left(P_{i}\right), C C\left(\bar{P}_{i}^{w}\right), C C^{w}\left(\bar{P}_{i}\right)$, and $I^{w}\left(P_{i}\right)$ using the comparative approaches into Figure 5. Additionally, the ultimate priority ranking orders of the five candidate alternatives

Table 3 Comparison of the obtained results.

\begin{tabular}{cccccc}
\hline$z_{\boldsymbol{i}}$ & $\mathbf{C C}\left(\mathbf{P}_{\mathbf{i}}^{\mathbf{W}}\right)$ & $\mathbf{C} \mathbf{C}^{\mathbf{W}}\left(\mathbf{P}_{\mathbf{i}}\right)$ & $\mathbf{C C}\left(\overline{\mathbf{P}}_{\mathbf{i}}^{\mathbf{W}}\right)$ & $\mathbf{C C}{ }^{\mathbf{W}}\left(\overline{\mathbf{P}}_{\mathbf{i}}\right)$ & $\mathbf{I}^{\mathbf{w}}\left(\mathbf{P}_{\mathbf{i}}\right)$ \\
\hline$z_{1}$ & 0.5380 & 0.4217 & 0.5463 & 0.4286 & 0.3665 \\
$z_{2}$ & 0.8600 & 0.7259 & 0.8712 & 0.7480 & 0.6186 \\
$z_{3}$ & 0.6156 & 0.6252 & 0.6345 & 0.6231 & 0.6432 \\
$z_{4}$ & 0.5898 & 0.5858 & 0.6033 & 0.5911 & 0.6318 \\
$z_{5}$ & 0.3164 & 0.3411 & 0.3287 & 0.3288 & 0.4578 \\
\hline
\end{tabular}

Table 4 Comparison of methodological core concepts.

PF, Pythagorean fuzzy; TOPSIS, technique for order preference by similarity to ideal solutions. 


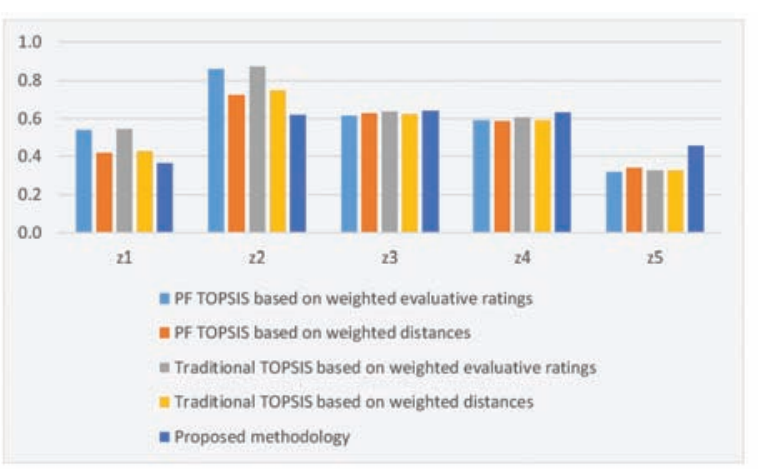

Figure $5 \mid$ Contrast of the obtained $C C\left(P_{i}^{w}\right), C C^{w}\left(P_{i}\right)$, $C C\left(\bar{P}_{i}^{w}\right), C C^{w}\left(\bar{P}_{i}\right)$, and $I^{w}\left(P_{i}\right)$ using the comparative approaches.

rendered by the comparative approaches are contrasted in Figure 6. The consistent finding in the comparative analysis is that the alternatives $z_{2}, z_{3}$, and $z_{4}$ are the more appropriate rehabilitation treatments for hospitalized stroke patients at acute stage. Moreover, the priority rankings produced by the four comparative approaches are the same. Namely, the priority ranking is determined as $z_{2}>z_{3}>$ $z_{4}>z_{1}>z_{5}$ regardless of the comparison bases of $C C\left(P_{i}^{w}\right)$, $C C^{w}\left(P_{i}\right), C C\left(\bar{P}_{i}^{w}\right)$, and $C C^{w}\left(\bar{P}_{i}\right)$.

From Figure 6, one can find that the ranking results yielded by the two distance-based PF TOPSIS methods are identical to the results rendered by the two distance-based traditional TOPSIS methods. In contrast to the four comparative approaches mentioned above, the proposed methodology generated a different priority ranking: $z_{3}>z_{4}>z_{2}>z_{5}>z_{1}$. The most prominent difference exists in the ranking orders is the alternative in first place. The alternative $z_{2}$ is ranked first based on the descending order of $C C\left(P_{i}^{w}\right), C C^{w}\left(P_{i}\right)$, $C C\left(\bar{P}_{i}^{w}\right)$, and $C C^{w}\left(\bar{P}_{i}\right)$, whereas the alternative $z_{3}$ is top-ranked by $I^{w}\left(P_{i}\right)$. Because the modified score function can provide a simple and convenient manner to compare the magnitudes of $P F$ evaluative ratings, this paper investigates the detailed evaluation data of the alternatives $z_{2}$ and $z_{3}$ to examine the effectiveness and reasonability the obtained results.

For the positioning treatment $\left(z_{2}\right)$, the following results using the modified score function were obtained: $\bar{p}_{21}=0.1200, \bar{p}_{22}=$ $0.1300, \bar{p}_{23}=0.2425, \bar{p}_{24}=0.4153, \bar{p}_{25}=0.7128, \bar{p}_{26}=0.5185$,

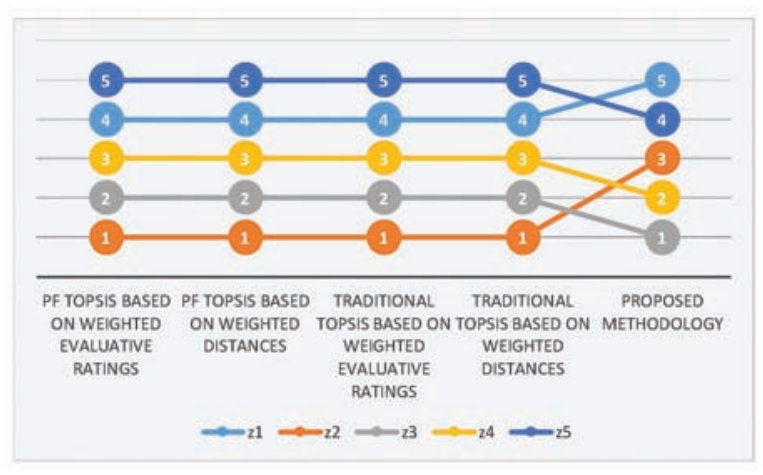

Figure 6 Contrast of the obtained priority ranking orders in the comparative analyses. $\bar{p}_{27}=0.3410$, and $\bar{p}_{28}=0.2072$. For the passive range of motion $\left(z_{3}\right)$, the following results were acquired: $\bar{p}_{31}=0.7288, \bar{p}_{32}=$ $0.9802, \bar{p}_{33}=0.1300, \bar{p}_{34}=0.3020, \bar{p}_{35}=0.2818, \bar{p}_{36}=0.4584$, $\bar{p}_{37}=0.5052$, and $\bar{p}_{38}=0.4892$. Recall that $C_{\mathrm{B}}=\left\{c_{1}, c_{2}, \cdots, c_{6}\right\}$ and $C_{\mathrm{C}}=\left\{c_{7}, c_{8}\right\}$. Because $\bar{p}_{21}<\bar{p}_{31}$ and $\bar{p}_{22}<\bar{p}_{32}, z_{2}$ performs better than $z_{3}$ with respect to the cost criteria $c_{1}$ and $c_{2}$. However, $z_{3}$ performs better than $z_{2}$ in terms of the remaining criteria. More specifically, it is clear that $\bar{p}_{23}>\bar{p}_{33}, \bar{p}_{24}>\bar{p}_{34}, \bar{p}_{25}>\bar{p}_{35}$, and $\bar{p}_{26}>\bar{p}_{36}$ with respect to the cost criteria $c_{3}, c_{4}, c_{5}$, and $c_{6}$; moreover, $\bar{p}_{27}<\bar{p}_{37}$ and $\bar{p}_{28}<\bar{p}_{38}$ about the benefit criteria $c_{7}$ and $c_{8}$. That is, $z_{3}$ is superior to $z_{2}$ in regard to the six criteria (i.e., $c_{3}-$ $c_{8}$ ). In contrast, $z_{2}$ is superior to $z_{3}$ only on the two criteria (i.e., $c_{1}$ and $c_{2}$ ). Thus, it is obvious that the passive range of motion is more appropriate than the positioning treatment (i.e., $z_{3}>z_{2}$ ) for inpatient stroke rehabilitation. Therefore, the obtained result yielded by the proposed methodology is more reasonable and acceptable than those generated by the two distance-based PF TOPSIS methods and the two distance-based traditional TOPSIS methods.

Based on the application results of the inpatient stroke rehabilitation case, the developed PF TOPSIS method using PF correlationbased closeness indices has rationality and effectiveness to assist rehabilitation care services with cerebrovascular diseases. Moreover, the proposed PF TOPSIS methodology is highly appealing in dealing with complex PF uncertainty as it allows for greater flexibility in regard to the separation measures and traditional relative closeness by employing the new PF correlations. Furthermore, the data processing steps in the proposed algorithmic procedure are relatively simple and effective to avoid the loss of original PF uncertain information. More importantly, the proposed methodology is performed around the new concepts of weighted PF correlation coefficients and Types I and II closeness measures, while the uniformity of the core structure of classical TOPSIS is still maintained.

\section{CONCLUSIONS}

TOPSIS is one of the famous MCDA methods. This paper has focused on the extensions of TOPSIS applied in complicated decision environments based on PF sets. PF sets have the capability of handling more uncertainty, and hence, the PF theory has been utilized to assess and improve complex MCDA problems in this study. Based on certain useful concepts of correlation measures and PF correlation-based closeness indices, the proposed PF TOPSIS methodology would produce more accurate and robust results, as demonstrated in the practical application of inpatient stroke rehabilitation at acute stage. Furthermore, the application results can assist the rehabilitation care services for stroke patients and subsequent nursing care.

In the hospitalization rehabilitation case, the results yielded by the proposed PF TOPSIS methodology have been compared with the results generated by some previous studies, and partial differences have been observed between them. Based on the comparative discussions, the obtained results based on PF correlationbased closeness indices has shown a desirable degree of reasonability. More importantly, the combination of the core structure of TOPSIS with PF information can compensate for the lack of certainty, and allow the decision maker to arrive at an acceptable solution. Further, the proposed methodology can determine the priority ranking orders of alternatives and acquire the best compromise 
solution within the environment involving the objective complexity of MCDA problems and the uncertainty of human subjective judgments.

In future research, the PF TOPSIS method can be considered to be used in a multipurpose decision-making system for a wide range of applications. Concretely speaking, in the future work, the proposed methodology can be applied to address multiple criteria evaluation problems in various fields, such as logistics planning [37], situation assessment [38], credit risk evaluation [7], new product development [39], and so on. Another orientation for future research could extend the proposed methodology to deal with large-scale group decision-making problems $[40,41]$, bi-level decision-making problems [42, 43], tri-level decision-making problems [44, 45], and fuzzy multilevel decision-making problems [46] for enhancing theoretical value and merits of the study.

\section{ACKNOWLEDGMENTS}

The authors acknowledge the assistance of the respected editor and the anonymous referees for their insightful and constructive comments, which helped to improve the overall quality of the paper. The authors are grateful for grant funding support from the Taiwan Ministry of Science and Technology (MOST 105-2410-H-182-007-MY3) and Chang Gung Memorial Hospital (BMRP 574 and CMRPD2F0203) during the study completion.

\section{REFERENCES}

[1] G. Dwivedi, R.K. Srivastava, S.K. Srivastava, A generalised fuzzy TOPSIS with improved closeness coefficient, Expert Syst. Appl. 96 (2018), 185-195.

[2] M. Gul, E. Celik, N. Aydin, A. Taskin Gumus, A.F. Guneri, A state of the art literature review of VIKOR and its fuzzy extensions on applications, Appl. Soft Comput. 46 (2016), 60-89.

[3] C.-L. Hwang, K. Yoon, Multiple Attribute Decision Making: Methods and Applications, Springer-Verlag, Berlin/Heidelberg/New York, 1981.

[4] K. Yoon, A reconciliation among discrete compromise solutions, J. Oper. Res. Soc. 38(3) (1987), 277-286.

[5] C.-L. Hwang, Y.-J. Lai, T.-Y. Liu, A new approach for multiple objective decision making, Comput. Oper. Res. 20(8) (1993), 889-899.

[6] S. Sadic, J.P. de Sousa, J.A. Crispim, A two-phase MILP approach to integrate order, customer and manufacturer characteristics into Dynamic Manufacturing Network formation and operational planning, Expert Syst. Appl. 96 (2018), 462-478.

[7] F. Shen, X. Ma, Z. Li, Z. Xu, D. Cai, An extended intuitionistic fuzzy TOPSIS method based on a new distance measure with an application to credit risk evaluation, Inf. Sci. 428 (2018), 105-119.

[8] S. Abdullah, S. Ayub, I. Hussain, B. Bedregal, M.Y. Khan, Analyses of S-boxes based on interval valued intuitionistic fuzzy sets and image encryption, Int. J. Comput. Int. Syst. 10(1) (2017), 851-865.

[9] G. Büyüközkan, S. Güleryüz, Multi criteria group decision making approach for smart phone selection using intuitionistic fuzzy TOPSIS, Int. J. Comput. Int. Syst. 9(4) (2016), 709-725.

[10] G. Büyüközkan, I.B. Parlak, A.C. Tolga, Evaluation of knowledge management tools by using an interval type-2 fuzzy TOPSIS method, Int. J. Comput. Int. Syst. 9(5) (2016), 812-826.
[11] X. Geng, X. Gong, X. Chu, Component oriented remanufacturing decision-making for complex product using DEA and interval 2-tuple linguistic TOPSIS, Int. J. Comput. Int. Syst. 9(5) (2016), 984-1000

[12] T. Wu, X. Liu, F. Liu, An interval type-2 fuzzy TOPSIS model for large scale group decision making problems with social network information, Inf. Sci. 432 (2018), 392-410.

[13] T.-Y. Chen, A novel risk evaluation method of technological innovation using an inferior ratio-based assignment model in the face of complex uncertainty, Expert Syst. Appl. 95 (2018), 333-350.

[14] F. Farajpour, A. Yousefli, Information flow in supply chain: a fuzzy TOPSIS parameters ranking, Uncertain Supply Chain Manag. 6(2) (2018), 181-194.

[15] R. Sehgal, D. Mehrotra, M. Bala, Prioritizing the refactoring need for critical component using combined approach, Decis. Sci. Lett. 7(3) (2018), 257-272.

[16] B. Cayir Ervural, S. Zaim, O.F. Demirel, Z. Aydin, D. Delen, An ANP and fuzzy TOPSIS-based SWOT analysis for Turkey's energy planning, Renew. Sust. Energ. Rev. 82(1) (2018), 1538-1550.

[17] H.S. Tooranloo, A.S. Ayatollah, M. Karami, IT outsourcing through group decision-making based on the principles of interval-valued intuitionistic fuzzy theory, Int. J. Procurement Manag. 11(1) (2018), 96-112.

[18] S. Xian, Y. Dong, Y. Liu, N. Jing, A novel approach for linguistic group decision making based on generalized interval-valued intuitionistic fuzzy linguistic induced hybrid operator and TOPSIS, Int. J. Intell. Syst. 33(2) (2018), 288-314.

[19] R.R. Yager, Pythagorean membership grades in multicriteria decision making, IEEE Trans. Fuzzy Syst. 22(4) (2014), 958-965.

[20] R.R. Yager, A.M. Abbasov, Pythagorean membership grades, complex numbers, and decision making, Int. J. Intell. Syst. 28(5) (2013), 436-452.

[21] X. Zhang, Multicriteria Pythagorean fuzzy decision analysis: a hierarchical QUALIFLEX approach with the closeness indexbased ranking methods, Inf. Sci. 330 (2016), 104-124.

[22] X. Zhang, Z. Xu, Extension of TOPSIS to multiple criteria decision making with Pythagorean fuzzy sets, Int. J. Intell. Syst. 29(12) (2014), 1061-1078.

[23] T.-Y. Chen, An interval-valued Pythagorean fuzzy outranking method with a closeness-based assignment model for multiple criteria decision making, Int. J. Intell. Syst. 33(1) (2018), 126-168.

[24] T.-Y. Chen, Remoteness index-based Pythagorean fuzzy VIKOR methods with a generalized distance measure for multiple criteria decision analysis, Inf. Fusion 41 (2018), 129-150.

[25] X. Peng, H. Yuan, Y. Yang, Pythagorean fuzzy information measures and their applications, Int. J. Intell. Syst. 32(10) (2017), 991-1029.

[26] H. Garg, A novel correlation coefficient between Pythagorean fuzzy sets and its applications to decision-making processes, Int. J. Intell. Syst. 31(12) (2016), 1234-1252.

[27] V. Mohagheghi, S.M. Mousavi, B. Vahdani, Enhancing decisionmaking flexibility by introducing a new last aggregation evaluating approach based on multi-criteria group decision making and Pythagorean fuzzy sets, Appl. Soft Comput. 61 (2017), 527-535.

[28] X. Peng, Y. Yang, Some results for Pythagorean fuzzy sets, Int. J. Intell. Syst. 30(11) (2015), 1133-1160.

[29] J.-C. Wang, T.-Y. Chen, Multiple criteria decision analysis using correlation-based precedence indices within Pythagorean fuzzy uncertain environments, Int. J. Comput. Int. Syst. 11(1) (2018), 911-924. 
[30] G. Wei, M. Lu, Pythagorean fuzzy power aggregation operators in multiple attribute decision making, Int. J. Intell. Syst. 33(1) (2018), $169-186$

[31] W. Xue, Z. Xu, X. Zhang, X. Tian, Pythagorean fuzzy LINMAP method based on the entropy theory for railway project investment decision making, Int. J. Intell. Syst. 33(1) (2018), 93-125.

[32] S. Zeng, J. Chen, X. Li, A hybrid method for Pythagorean fuzzy multiple-criteria decision making, Int. J. Inf. Tech. Decis. 15(2) (2016), 403-422.

[33] D. Liang, Z. Xu, The new extension of TOPSIS method for multiple criteria decision making with hesitant Pythagorean fuzzy sets, Appl. Soft Comput. 60 (2017), 167-179.

[34] M. Gul, M.F. Ak, A comparative outline for quantifying risk ratings in occupational health and safety risk assessment, J. Clean. Prod. 196 (2018), 653-664.

[35] D. Liang, Z. Xu, D. Liu, Y. Wu, Method for three-way decisions using ideal TOPSIS solutions at Pythagorean fuzzy information, Inf. Sci. 435 (2018), 282-295.

[36] J. Zhou, W. Su, T. Baležentis, D. Streimikiene, Multiple criteria group decision-making considering symmetry with regards to the positive and negative ideal solutions via the Pythagorean normal cloud model for application to economic decisions, Symmetry. 10(5) (2018), 140.

[37] G. Zhang, J. Ma, J. Lu, Emergency management evaluation by a fuzzy multi-criteria group decision support system, Stoch. Environ. Res. Risk Assess. 23(4) (2009), 517-527.
[38] J. Lu, G. Zhang, R. Da, Intelligent multi-criteria fuzzy group decision-making for situation assessments, Soft Comput. 12(3) (2008), 289-299.

[39] J. Lu, J. Ma, G. Zhang, Y. Zhu, X. Zeng, L. Koehl, Theme-based comprehensive evaluation in new product development using fuzzy hierarchical criteria group decision-making method, IEEE Trans. Ind. Electron. 58(6) (2011), 2236-2246.

[40] R.M. Rodríguez, Á. Labella, G.D. Tré, L. Martínez, A large scale consensus reaching process managing group hesitation, Knowl. Based Syst. 159 (2018), 86-97.

[41] Z. Zhang, C. Guo, L. Martínez, Managing multigranular linguistic distribution assessments in large-scale multiattribute group decision making, IEEE Trans. Syst. Man Cybern. Syst. 47(11) (2017), 3063-3076.

[42] G. Zhang, J. Han, J. Lu, Fuzzy bi-level decision-making techniques: a survey, Int. J. Comput. Int. Syst. 9(1) (2016), 25-34.

[43] Y. Zheng, G. Zhang, J. Han, J. Lu, Pessimistic bilevel optimization model for risk-averse production-distribution planning, Inf. Sci. 372 (2016), 677-689.

[44] J. Han, J. Lu, Y. Hu, G. Zhang, Tri-level decision-making with multiple followers: model, algorithm and case study, Inf. Sci. 311 (2015), 182-204.

[45] J. Han, G. Zhang, Y. Hu, J. Lu, A solution to bi/tri-level programming problems using particle swarm optimization, Inf. Sci. 370 371 (2016), 519-537.

[46] J. Lu, J. Han, Y. Hu, G. Zhang, Multilevel decision-making: a survey, Inf. Sci. 346-347 (2016), 463-487. 